OPEN ACCESS

Edited by:

Silvia Serino,

Lausanne University Hospital (CHUV),

Switzerland

Reviewed by:

David Bryce Yaden,

University of Pennsylvania,

United States

Marianna Obrist

University of Sussex, United Kingdom

Simon Richir,

Arts et Métiers ParisTech, France

*Correspondence:

Ekaterina R. Stepanova erstepan@sfu.ca

Specialty section

This article was submitted to

Human-Media Interaction

a section of the journal

Frontiers in Digital Humanities

Received: 01 June 2018

Accepted: 01 April 2019

Published: 25 April 2019

Citation:

Stepanova ER, Quesnel D and Riecke BE (2019) Space-A Virtual Frontier: How to Design and Evaluate a Virtual Reality Experience of the

Overview Effect.

Front. Digit. Humanit. 6:7. doi: 10.3389/fdigh.2019.00007

\section{Space-A Virtual Frontier: How to Design and Evaluate a Virtual Reality Experience of the Overview Effect}

\author{
Ekaterina R. Stepanova*, Denise Quesnel and Bernhard E. Riecke \\ iSpace Lab, School Of Interactive Arts and Technology, Simon Fraser University, Surrey, BC, Canada
}

A select small group of people have an amazing opportunity to see the Earth from a unique perspective-from space. The effect this experience has on an individual has been described as extraordinary and profound, consisting of a cognitive shift in worldview that leads to a deeper understanding of the fragility and vulnerability of our planet, and an increased feeling of connectedness. This experience, termed the "Overview Effect," has been reported by many space-travelers. Its key outcome-an enhanced feeling of interconnectedness - contributes to both one's well-being and the sense of responsibility for the Earth. If this profoundly positive experience could be made accessible to more people than just space-travelers, this might ultimately contribute to a healthier and more caring society, where more individuals deeply feel the interconnection of all living beings and responsibility for our collective future. Given virtual reality (VR) technology's potential to induce experiences affecting an immersant in a similar way as a real experience, we see an opportunity to leverage this technology to attempt to elicit the Overview Effect as a virtual experience. Through a virtual installation, the experience could be made accessible to people around the world, and for researchers to study this otherwise rare phenomenon. This article builds the case for VR as a tool for inducing and studying the Overview Effect. It reviews the psychological research on the Overview Effect and awe, and proposes guidelines for: (1) the design of VR experiences to elicit an Overview Effect and (2) evaluation methods for assessing if, or to what degree, the experience was achieved. Finally, we discuss existing implementations of the Overview Effect in VR. Thus, we are making an applied contribution in the form of design guidelines, and contributions to knowledge in the form of a review of research related to the Overview Effect. We invite researchers and VR creators to utilize and expand on the guidelines proposed in this paper to design transformative VR experiences that induce positive change, and promote a feeling of connectedness and care for each other, and our Spaceship Earth.

Keywords: virtual reality, overview effect, transformative experience, design guidelines, cognitive shift, interconnectedness, awe 


\section{INTRODUCTION}

Our world is facing a lot of challenges in the domains of the environment, climate change, sustainability, over-consumption, and social stability. While these challenges require complex solutions, still, on an individual level, there are some wellknown small steps each person could take to help protect the environment and minimize social tensions. Despite this intellectual awareness, many people still neglect to take the required action. It seems that many people may not perceive the connection between their individual actions and the global processes in the world (Blumstein and Saylan, 2007). If we could promote the feeling of connection within individuals, that could support the development of a more global consciousness, which may, in turn, assist with more people caring and taking responsibility for the collective future of our planet. Additionally, we are observing growing rates of mental disorders, such as depression (Whiteford et al., 2013; World Health Organization, 2017). People often feel isolated and lack profound social connections, which can contribute to increased depression and detachment. Despite rapid developments of technology designed to facilitate communication and connection between people, such technology is often (although not always) associated with the opposite effect of increased loneliness and depression (Kraut et al., 1998; Kross et al., 2013).

Thus, experiences that can promote the feeling of connection are very valuable as a step toward a healthier, happier and more caring society. So how can we promote the feeling of connectedness? One inspiration may come from a rare but powerful experience that appears to have this exact effect: it's the experience that astronauts have when they see the Earth from outer space. In his book "The Overview Effect: Space exploration and human," White (1998) analyzed reports of astronauts about this experience, and introduced a term for it-the "Overview Effect" (OE). Micheal Collins, a space pilot, described the importance of the OE:

"I think the view from 100,000 miles could be invaluable in getting people together to work out joint solutions, by causing them to realize that the planet we share unites us in a way far more basic and far more important than differences in skin color or religion or economic system."

(White, 2014, p. 109).

The OE has been shown to have lasting positive effects both on individuals (Ritsher et al., 2005; Suedfeld et al., 2012) and society, as evident from a lot of astronauts joining humanitarian and proenvironmental movements after returning from space (Ihle et al., 2006; Garan, 2015). Nezami (2017) has also explored the OE's potential for psychological therapy and well-being. The findings show that the $\mathrm{OE}$ is a profoundly positive experience that can improve an individual's wellness, and promote awareness, prosocial and pro-environmental attitudes in society. If we could provide more people with a similarly profound experience as the astronauts fortunate enough to have experienced it, we may contribute to a healthier and more connected society where taking care of each other and the planet would seem obvious and natural instead of an extra burden. Yet, it is not feasible to send large numbers of people into space with the sole aim of having a profound emotional experience, especially given the high cost, risk, environmental footprint, and physical demands of spaceflight. However, if we better understand what are the key triggers of the $\mathrm{OE}$, we might ultimately be able to simulate this experience on Earth.

This presents a perfect opportunity for Virtual Reality (VR) technology to provide the researchers and designers with a means to study this rare, profound phenomenon, and develop virtual experiences for positive change. The immersive powers of VR allow the immersant to experience being in distant places and be affected by that experience without actually going there (Sanchez-Vives and Slater, 2005). This technological breakthrough is providing us with an opportunity to make the $\mathrm{OE}$ more accessible to researchers and the general public. While VR probably won't be able to provide an experience as powerful as the OE experienced by space-travelers, recent research shows that it has the potential of eliciting at least some aspects of the OE (Chirico et al., 2018; Quesnel and Riecke, 2018; Stepanova et al., in press), supporting its potential to inviting at least a smaller degree of the OE in participants on Earth. However, the extent to which VR technology would be able to elicit a transformative experience such as the $\mathrm{OE}$ remains an open research question.

In order to build the case for VR being a tool capable of eliciting the $\mathrm{OE}$, this paper first summarizes the relevant research suggesting that VR technology is capable of inducing an experience that could lead to a positive change. Since $\mathrm{OE}$ is a rare and complex phenomenon, there is little academic research on this topic. Some important steps toward building an understanding of its effects, components, triggers and progression have been taken (Gallagher et al., 2015; Yaden et al., 2016; Nezami, 2017), however a lot more research needs to be done before we can develop a complete understanding of the phenomenon. The primary focus of this paper is to analyze existing research and reports of the $\mathrm{OE}$, and extract specific design guidelines from the research for the creation of a VR experience that could elicit a transformative experience similar to the OE. Secondly, we are suggesting evaluation methods on whether/to what extent the VR experience was able to induce the $\mathrm{OE}$, and methods for studying this transformative phenomenon elicited in VR.

To achieve these two goals, we are analyzing the spacetravelers reports described and summarized in White (2014) and Gallagher et al. (2015) books on the OE, as well as the scientific research investigating this phenomenon (Yaden et al., 2016). We also draw from theories about transformative experience design (Gaggioli, 2016; Kitson et al., 2018; Stepanova et al., 2018). As such, this paper presents a focused psychological review on positive transformative experiences and proposes specific guidelines that can be implemented by VR developers. Therefore we are making applied contributions to the design field by providing research-based guidelines for the design of a positive transformative VR experience of an OE, as well as some contributions to knowledge within the field of psychology in a form of a review of the research and methods related to studying the OE (Figure 1). 


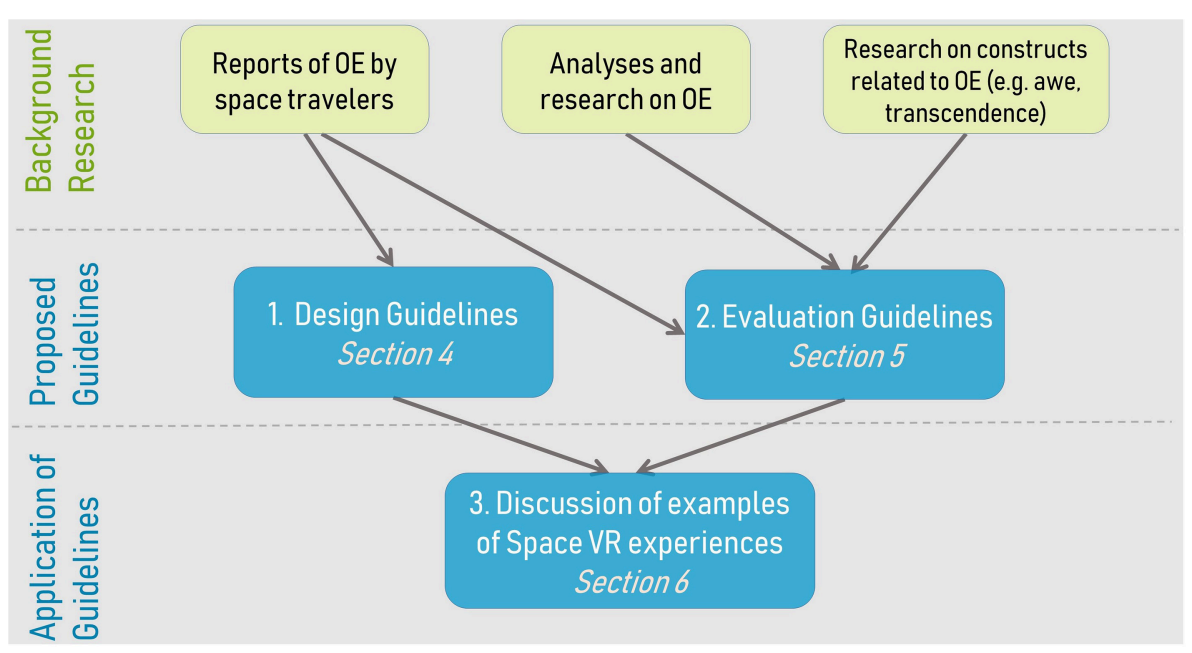

FIGURE 1 | The diagram illustrating the general structure of the current paper and its contributions.

Finally, we discuss some of the existing VR applications inspired by spaceflight experiences, and make a tentative comparison between them and our guidelines. We applied some of the proposed design guidelines ourselves by iteratively designing a prototype of an immersive experience inspired by the OE (Quesnel et al., 2018b), which we evaluated in a study using some of the methods proposed in this paper (Stepanova et al., in press); however, comprehensive discussion of this prototype is outside of the scope of this paper and can be found in the above mentioned publications.

\section{VIRTUAL REALITY FOR POSITIVE CHANGE}

In recent years, VR technology is rapidly becoming more capable, affordable, and accessible to people, which has prompted the scientific community to explore its potential to be used for research, and for improving human lives.

\subsection{The Mechanism of How VR Can Influence Individuals}

First, it's important to discuss the theoretical assumptions that lead us to believe that VR technology can have a strong effect on an individual's cognition and behavior. When analyzing the effects of VR, we need to be aware of the assumptions of the psychological theories that this field is grounding itself in.

Our worldview is based on our experiences: through sensory systems, we observe events in the world, and build a cognitive model that can account for these experiences. However, the sensory information we are receiving from the world is often incomplete and in certain cases could be conflicting. To deal with this, our cognitive system relies on multi-sensory integration to register an event. In case of a conflict between multiple sensory inputs, we tend to be biased toward the senses that are stronger, or have higher acuity in humans (Welch and
Warren, 1980). For instance, a visual stimulus will usually dominate auditory stimuli as famously observed in the McGurck effect (McGurk and MacDonald, 1976) and ventriloquist illusion (Bonath et al., 2007). Moreover, this effect is prominent even with large conflicts between stimuli that can't be merged into a single event perception: with repeated exposure to conflicting stimuli, our cognitive system adjusts and forms a biased perception. For example, a repeated conflict between visual feedback for a pointing task and spatial memory will bias our spatial perception for all future stimuli by the length of the discrepancy between the received feedback and the memory of the position of the target (Lipinski et al., 2010). Anecdotally, everyone can observe this phenomenon of learning through sensory integration when they step on a non-moving escalator and feel unbalanced and disoriented.

In the context of VR, this effect of multi-sensory integration has been studied in relation to the body ownership illusion (the illusion of experiencing an artificial or virtual limb as a part of one's own body) (Maselli et al., 2016), suggesting that the visual input received through a VR head-mounted display indeed integrates with other sensory inputs in a similar manner to a visual input received from the real world. Another example of multi-sensory integration in VR is vection (self-motion illusion) (Riecke, 2010) - the compelling sensation of self-motion induced by the visual or auditory stimulus akin to the sensation experienced when seeing a train starting to move from a window of one's stationary train. This mechanism of our cognitive system makes immersive VR technology extremely potent to create experiences that in effect, might be indistinguishable from real world experiences. We see this in the example of vection, where the illusion of self-motion can no longer be distinguished from actual self-motion (Brandt et al., 1973). A common critique of the potential of VR technology at present is that it doesn't always have comprehensive sensory information, such as haptic, or olfactory capabilities. However, the combination of the multisensory integration and a high reliance on visual channel (for 
human species) provides VR with enough power to create experiences that can affect the structure of our cognitive model akin to real world events. Even when the VR system doesn't produce a perfectly complete experience for all of our sensory channels (e.g., lack of haptic or vestibular input), our mind will fill in these gaps based on the available input (e.g., visual and auditory).

Embodied cognition is another theory that explains how VR experiences can affect our cognition (Bailey et al., 2016). According to this theory, the mind is not "locked" within one's brain, but rather is heavily based on our body (Wilson, 2002). Consequently, an immersive VR experience that engages one's body in the experience will affect cognition on a stronger and deeper level than a solely visual experience in less immersive media. VR tends to elicit more realistic behaviors and reactions due to a feeling of embodiment and use of multisensory input (Slater, 2011; Wilson and Soranzo, 2015).

\subsection{Evidence of Transformative Powers of VR}

In recent decades, VR technology has been rapidly developing and many researchers have been investigating VR's psychological and societal application and ability to induce positive change in an immersant. An extensive review of VR applications for mental health provided by Riva et al. (2016) and Freeman et al. (2017) shows the growing potential of the technology. Jeremy Bailenson's lab at Stanford University studies the social application of virtual experiences and how it can induce positive behavioral change; for instance, Rosenberg et al. (2013) study observed increased pro-social behavior in participants who flew like a superman around a virtual city. In a different experiment by Ahn et al. (2014), participants performed more pro-environmental behavior after virtually cutting down a tree. Another study with immersive VR have shown learning gains about climate science in 270 participants who took a 'field trip' under water in VR to observe effects of ocean acidification (Markowitz et al., 2018). The type of a virtual body can have an effect on participant's experience of body-ownership and the behavior (Gorisse et al., 2019). These effects of virtually embodying a body other than one's own have been extensively explored: taller avatars would argue more aggressively (Yee et al., 2009), slimmer avatars have smaller body image (Serino et al., 2016); the cognitive effects are shown in increased connection to nature after embodying a cow (Ahn et al., 2016); stereotyping and biases get reduced when embodying an avatar of outer-group (Maister et al., 2015), stereotyping against elderly is reduced when embodying an older avatar (Yee and Bailenson, 2006), likewise embodying an other-race avatar reduces racial biases (Peck et al., 2013; Banakou et al., 2016; Hasler et al., 2017), while having a virtual out-of-body experience reduces the fear of death (Bourdin et al., 2017). Notably, becoming homeless in VR elicits long lasting (up to 8 weeks) positive attitudes toward homeless and increases the chances that participants will sign a petition for affordable housing (Herrera et al., 2018). This compelling evidence from academic research shows that even a few minutes of a VR experience can impact our behavior and worldview, at least for a short-term (immediately after the VR experience, when the measures are taken, or a few weeks after). Specifically, given the previous studies findings on VR eliciting pro-social and pro-environmentalist behavior, and considering the $\mathrm{OE}$ is characterized by similar changes in space travellers, we have reason to believe that a well-designed virtual experience of a spaceflight might eventually be able to induce an OE and lead to the cognitive shift and behavioral change associated with the OE. Additionally, it would be important to assess the larger long-term (over a year) effects of such experiences.

\section{A SUMMARY OF THE OVERVIEW EFFECT}

The term "Overview Effect" (OE) was first coined by Frank White in his book (White, 1998), where he describes this profound experience reported by astronauts who saw the Earth from outer space. White describes it as a cognitive shift, or shift in awareness that resulted in a new worldview leading to an enhanced sense of responsibility for Earth. This effect is reported by most astronauts and space-travelers, but can be described differently by each individual. However, these descriptions have common characteristics that suggest that it is a singular phenomenon. The descriptions start with the admiration of the overwhelming beauty of the Earth and realization of its fragility leading to the feeling and understanding of interconnectedness of all life, and the concern and responsibility for our home planet and its inhabitants.

\subsection{Possible Explanations of the $\mathrm{OE}$}

Even though $\mathrm{OE}$ is a rare phenomenon making it difficult to build a comprehensive understanding of its causes and progression, there are a number of proposed theories that could explain the mechanism of $\mathrm{OE}$, which we will discuss below.

\subsubsection{Dissonance}

In his foreword to the third addition of Frank White's book (White, 2014, p. xiii), astronaut Ron Garan describes his own experience of $\mathrm{OE}$ :

"At its core is the contradiction between the beauty of our planet and the unfortunate realities of life on the surface for many of its inhabitants."

Ron Garan, author of the book "The Orbital Perspective" (Garan, 2015) identifies the key mechanism through which OE develops to be the emergence of a dissonance between the observed and perceived reality. Our cognitive system strives to be in an equilibrium, thus it adjusts when a dissonance is introduced and the system has to adjust to reduce it. This mechanism, for example, is illustrated in the theory of cognitive dissonance (Festinger, 1962), which explains the alignment of one's mental model and behavior and consequently can be used to modify the behavior or the mental model. The similar process of accommodation explains how the mental model is adjusting to incorporate a new profound perceptual experience, as was described as one of the key processes of the experience of a transformative emotion awe (Keltner and Haidt, 2003) as well 
as later, more generally integrated in a transformative experience design framework (Gaggioli, 2016). Thus, encountering this new perspective on Earth from space pushes space-travelers to reassess their existing mental model when attempting to assimilate their experience. If this new experience introduces a dissonance into the cognitive model, the model will have to be adjusted to reduce the dissonance and accommodate the new experience, thus producing a cognitive shift, when

\section{"the physical and mental realities are brought into alignment."}

(White, 2014, p. 17)

Edgar Mitchell described it as an "aha" experience:

\begin{abstract}
"To me the difference between getting and not getting an "aha" experience of it is whether it shifts your structure a bit. Do you get a sense of freedom, of expansiveness, because you've just experienced something that is different from your previous experiences and beliefs"
\end{abstract}

(White, 2014, p. 25)

As such, the VR experience needs to be designed with a goal to induce this dissonance and facilitate accommodation, as discussed in Stepanova et al. (2018) and Gaggioli (2016).

\subsubsection{Transcendence and Awe}

Yaden et al. (2016) analyzed the interviews of astronauts and identified the emotion of awe and transcendent experiences as key components of the OE. Interestingly, research demonstrates that the traits and effects of both transcendent experiences and awe-inspiring experiences is strikingly similar to that of the OE. However, both transcendent and awe-inspiring experiences include a large spectrum of phenomena (Yaden et al., 2017a; Chirico and Yaden, 2018), and thus only some research from these domains will be relevant to the $\mathrm{OE}$. What complicates this is the lack of consistency in how the terms "awe" and "transcendent" experiences are used: both terms could be used to describe different phenomena, and other terms can be used to describe the same or a similar phenomenon (e.g., "peak experience," "light experience"). Here, we provide a short summary of a few relevant aspects of the research on transcendent and awe-inspiring experiences that can be used for better understanding and designing for the OE.

Transcendent experiences are describing a profound, usually spiritual experience leading to an expanded awareness and dissolution of one's ego and the feeling of global interconnectedness (Levin and Steele, 2005; Yaden et al., 2017a). Although often transcendent experiences are described through a spiritual interpretation, there is a variety of transcendent experiences that are not interpreted with a spiritual lens. Depending on their background, some astronauts may describe their experience of $\mathrm{OE}$ as a religious or spiritual experience, feeling connected to God, while others describe the feeling of unity with the world and our planet without spiritual interpretation. Even though the $\mathrm{OE}$ is only described as a spiritual experience by some of the astronauts, the description of the effects of the $\mathrm{OE}$ and transcendent experiences are fairly similar, so we can use our knowledge of transcendent experience to help understand the OE. Transcendent experiences are described in multiple different contexts, such as: yoga practice and meditation (Berkovich-Ohana and Glicksohn, 2017), flow states during sport and music practices (Csikszentmihalyi and Csikszentmihalyi, 1992), interaction with nature (Williams and Harvey, 2001; McDonald et al., 2009; Powell et al., 2012; Tsaur et al., 2013), near-death experiences (Greyson and Stevenson, 1980; Kohr, 1983) and several others. Yaden et al. (2017a) presents an overview of the spectrum of different selftranscendent experiences, among which awe, peak experiences and mystical experiences are probably the most relevant to the $\mathrm{OE}$. The main characteristic of transcendent experiences is the feeling of oneness with the universe, nature, the divine or God, depending on how it is interpreted by an individual. Other shared characteristics with the $\mathrm{OE}$ are an aesthetic pleasure of the experience, restructure of consciousness to encompass the new experience, transcendence of time and space, and positive changes in attitudes and behavior.

Awe-inspiring experiences could account for some of the effects of the OE. Awe is a psychological construct that is considered part of a "self-transcendent" index of emotions, and is characterized by the perception of something vast, followed by a need to accommodate the experience (Keltner and Haidt, 2003). The "vastness" that elicits awe can be both perceptual and conceptual, and as discussed in Yaden et al. (2016) in the case of the $\mathrm{OE}$, astronauts are likely experiencing both perceptual and conceptual vastness when observing our planet floating in outer space. The planet is perceived to look minuscule when compared to the surrounding universe (perceptual vastness), while simultaneously introducing complex ideas like the fragility of life (conceptual vastness).

Additionally, Yaden et al. (2016) explain that while it may be tempting to describe awe as a perceptual or aesthetic emotional experience in the case of viewing the Earth from space, there are a few unique features that factor into how this awe-inspiring experience promotes a feeling of connectedness. Among those is a sense of "totality":

"the tendency is, quite literally, to think in global terms, and that the ability to behold all at once the entire domain in which these human themes reside contributes to the overwhelming sense of awe"

(Yaden et al., 2016, p. 4).

The authors explain that seeing the Earth from above may disconnect an individual physically from their home but helps form an emotional connection that sees humankind as an entirety, connected to one another. A key characteristic of awe is the "small-self" perception, which is a feeling of one's personal identity receding and reducing in significance when faced with an awe-inspiring experience (Piff et al., 2015; Bai et al., 2017), a feeling akin to humility. This is seen in statements such as

"I feel the presence of something greater than myself"

(Piff et al., 2015, p. 6). 
Relating to self-diminishment, an individual may feel the need to assimilate into a social collective, which requires them to set aside their own self-interests and assume the needs of the group (Keltner and Haidt, 2003). In this regard, it should not be surprising that awe is often elicited at collective engagements, like concerts, rallies, and spiritual rituals (Shiota et al., 2004). Compared to other emotions, like pride, that are thought to promote a desire to belong to a social collective, individuals who experience awe report a stronger connection to collectives (Shiota et al., 2007). Also, awe is different from many positive emotions like joy, which results in self-focused attention (Keltner and Haidt, 2003; Shiota et al., 2007), whereas awe can significantly shift attention away from the self (Stellar et al., 2017). This experience of awe may be why seeing a conceptual wholeness of humanity in the form of the Earth is so profound for astronauts. Profound awe during the $\mathrm{OE}$ and its tendency to induce a perception of small-self (self-diminishment) is of great interest when exploring how individuals may feel, and demonstrate connectedness as a result of the experience.

\subsection{Negative Psychological Effects of a Spaceflight}

The spaceflight experience and the view of Earth from space is not solely described as a positive experience. The "breakoff" phenomenon-the feeling of separation from Earth often associated with anxiety has been reported by high altitude jet pilots (Clark and Graybiel, 1957; Sours, 1965), and is sometime mentioned in the context of spaceflight, but is not a wellresearched experience for astronauts. Stress and feelings of confinement and isolation (Morphew, 2001) and detachment (Valentine, 2016) can be experienced by astronauts. However, negative effects seem to be predominately associated with the physical stressors and serious dangers of a spaceflight, and thus would be less likely to occur in a VR experience.

\section{EXPERIENCE DESIGN GUIDELINES}

In this section we extract some common components of the description of the $\mathrm{OE}$ by astronauts and propose guidelines for the design of the VR experience for OE, including the setting, pre-VR, and post-VR components of the experience. The proposed design guidelines in this section were identified by a researcher analyzing and coding the interviews with astronauts reported in White (2014) for specific aspects that can be identified as conditions or triggers for the OE experience and transformed into design guidelines. The resulting components and guidelines were reviewed by a second researcher, and partially verified through discussing them with members of the Overview Effect Institute.

For designing a compelling VR experience, many factors need to be considered, including: comfort, presence, agency, immersion, flow, etc. (Stanney and Hale, 2014; Jerald, 2015; TchaTokey et al., 2015; Sherman and Craig, 2018). However, in this paper, we will leave these general factors aside and focus on aspects specific to $\mathrm{OE}$.

\subsection{Embodied Experience and Self-Relevance}

White discusses that

"our 'worldview' as a conceptual framework depends quite literally on our view of the world from a physical place in the universe"

(White, 2014, p. 1).

Moreover, it doesn't seem to be enough to hear the descriptions or see the images of the perspective; the actual embodied first person experience seems to be crucial for creating this new worldview or mental model. That is, the mere conceptual understanding is not enough to extend one's mental model, when it is not accompanied or elicited by an individual's embodied sensory experience. A number of astronauts were comparing the experience of seeing Earth with the experience of seeing the Grand Canyon:

"The first time you look out at the Earth and see that, it's a heart-
stopper. I don't care how many pictures you've seen of the Grand
Canyon, it's not the same as looking over the side and saying, 'My
goodness, it is really that deep"”

(White, 2014, p. 13).

Similarly, even though the first pictures taken from space after the first space missions left a strong impressions on general public, and, as Joseph Allen put it,

"you wouldn't have a gotten a penny for EPA [Environmental Protection Agency] before those pictures from orbit"

(White, 2014, p. 206),

they didn't seem to have been able to induce the OE in the general public. Sandy Magnus, an engineer and astronaut, explains the value of the first person sensory experience:

"There is a difference between intellectual knowledge and
experience-based knowledge. You know it is hot outside when you
hear it is 110 degrees, but you don't really know it's hot outside until
you walk out the door and you get blasted with a wall of heat hitting
you in the face. It is not an intellectual fact anymore; it is experience
that you have connected with that piece of data."

(White 2014, p. 45)

Even though intellectually astronauts knew, for instance, that there is no dividing boundaries on Earth between countries as we normally see on the globe and maps, seeing boundary elimination for themselves was still surprising, and that experience "provided a crystal clarity," as reported by Edward Gibson (White, 2014, p. 40). Thus, for a VR experience of the OE it is important to go beyond merely presenting the visual perspective of Earth viewed from outer space, but strive to provide the immersant with an embodied first-person experience of them traveling through space. What is crucial for achieving this is designing for the immersant's sense of self-relevance and agency in the environment, which was shown to play large role in virtual body ownership (Ma and Hommel, 2015) and could sometimes be used to explain the sense of 'presence' (Herrera et al., 2006). Presence in a virtual environment has multiple components: place illusion 
(the feeling of 'being there') needs to be complemented by plausibility illusions (the feeling that events in the virtual environment are real) in order to effect the immersant's behavior (Slater, 2009, 2011). Thus, the virtual environment should facilitate the plausibility illusion and appear responsive to the actions of the immersant. Adding subtle cues on multiple sensory channels could make this first-person embodied sensory experience even more likely to occur. Recent developments of multisensory technologies for VR could aid in supporting embodied experiences: olfactory devices (Morie et al., 2009; Risso et al., 2018), temperature (Ranasinghe et al., 2017), haptic (Pittera et al., 2017; Whitmire et al., 2018). For example, when the sun appears virtually, a heater could provide the experience of warmth coming from the perceived sunlight.

\subsection{Privacy and Social Space}

"The experience is relatively private while the astronaut is in space but becomes highly public on return"

(White, 2014, p. 12).

The fact that astronauts are being interviewed upon arrival might in fact make them process the experience in a new way. In regards to his experience of the $\mathrm{OE}$, Alan Bean describes how the experience was only contemplated and accommodated upon the media's request for an interview:

"You think about it only when people ask you. You were really refining other skills"

(White, 2014, p. 15).

While the spaceflight experience can often be very social, as usually astronauts work as a crew, the moment of the OE experience is still often described as private. It might be an interesting question to explore whether $\mathrm{OE}$ can be experienced and intensified as a virtual shared experience, since sharing an experience with another person can lead to a stronger experience (Boothby et al., 2014). However, given the descriptions of OE we would recommend to start with designing for a virtual $\mathrm{OE}$ as a private experience, since it might be important for creating a safe private space where a strong emotional experience can occur. Once we can achieve some level of OE, we can investigate how sharing this experience may amplify it.

While the privacy might have initially allowed for a profound experience to occur in space, the interviews for media upon return might have played a role in accommodating the experience for astronauts. Both stages are likely important for the full processing of the $\mathrm{OE}$, thus the designers of the VR experience will have to face a challenge of creating a space for a very private experience of Earthgazing, while also providing a social space to encourage discussion and processing of the experience after the person exits VR. We propose to introduce a private space for the main VR experience followed by a public space (for accommodation of the experience through sharing and discussion) as a methodological approach to implement this for VR experiences, as it attempts to replicate the real-life accommodation astronauts appear to benefit from.

\subsection{Visual Style}

\subsubsection{Vastness}

As discussed above, awe is identified as a key component of OE. Vastness is believed to be the key property of the stimulus capable of eliciting awe (Keltner and Haidt, 2003). Chirico et al. (2016) proposed to use VR to create awe-inspiring experiences, as it is capable of producing vast stimuli, and can induce presence and enhance the ecological validity of the experience. The virtual environment should be designed to highlight the vastness of space and possibly other environments that may be included in the virtual journey to build up the sense of awe. Klatzky et al. (2017) used photographs to analyze which properties of a stimuli would be associated with perception of vastness and found that openness and ruggedness were the predictive parameters, with highly open or moderately open, but rugged images being perceived as vast. However, designing vast stimulus in VR is not as straightforward as it may seem. Besides the technical limitations coming from the current VR headsets still having limited field of view and low resolution, leading to commonly observed distance underestimation in VR (Willemsen et al., 2009), the strategy for design of awe-inspiring vast stimuli is not simple. Rauhoeft et al. (2015) explored the specific properties of a an immersive virtual stimuli that would lead to perception of vastness. They used virtual landscapes that included fields, mountains and forests, and found that even though VR stimuli were successfully able to elicit the perception of vastness, the survey data revealed an open field to lead to the highest reported perception of vastness. This was surprising to the authors, and might be attributed to the definition of 'vastness' used:

"A space is vast if it seems to extend without limits away from you, making you feel like a small element within the space"

(Rauhoeft et al., 2015, p. 52),

thus participants might have conceptualized 'vastness' as a literally open space, rather than being in presence of something greater than themselves. In order to design the vast stimuli that can contribute to the $\mathrm{OE}$, developers need to strive for a combination of perceptually and conceptually vast virtual stimuli that can induce the feeling of presence of something greater than oneself.

\subsubsection{Suspending Disbelief Through Aesthetics}

Everyone who has seen the Earth from outer space has been deeply impressed by its beauty. The image seems indescribable, like nothing else experienced on Earth. Marc Garneau called his experience a

"dreamlike experience, because space is a very magical place to be"

(White, 2014, p. 218).

These descriptions of the marvelous view of the Earth suggest that the VR experience could be designed in a style of magical realism in order to create a similar dreamlike visual experience. We argue that opposed to hyper-real visual style, magical realism may be more effective at facilitating the suspension of disbelief in the immersant and engaging them emotionally. This would also help to bypass the imperfections of the technology at 
representing a realistic environment. To illustrate this point we rely on approaches used in art to engage participants and elicit an affective response.

Magical realism is an aesthetic style of art that incorporates a realistic portrayal of our world, with magical or mystical elements fantastical or ambiguous in concept. This style supports positive subjective appraisals of the visual scene while simultaneously experiencing something novel that their imagination can interact with (Faris, 2004). Ambiguity can make interactive systems and artwork more engaging (Gaver et al., 2003) and lead to stronger connection and meaning making between the participant and the installation through the principle of "Beholder's share" (Kandel, 2012), where participant's own experience contributes to the interpretation of an art filling up the gaps left by the ambiguous image. Visuals and art that is too abstract and difficult to understand, or on the flip side, too literal with concrete meaning, tend to elicit less positive emotions (Silvia, 2012). With the example of artist Char Davies 1995 VR installation "Osmose" (1996), we experience abstract visuals that do not directly illustrate, but rather suggest meaning that is open to interpretation in the mind of the immersant, promoting an imaginative and self-relevant experience, which is important for eliciting profound emotions. This might also be related to the 'imaginative immersion' component of the experience (Ermi and Mäyrä, 2005; Vidyarthi et al., 2012).

\subsubsection{Clarity and Contrast}

The image that astronauts see is very clear and vibrant, as Nicole Stott described it:

"dynamic, crystal-clear view that just glows"

(White, 2014, p. 18).

Often astronauts describe the image they have seen as being in high resolution full of detail. For example the first man in space, Yuri Gagarin says:

"The mountain ridges, the great rivers, massive forests, ocean
shorelines stood out sharply. I could see both clouds and their faint
shadows on the surface of the Earth"

(White, 2014, p. 27).

The first time the intense clarity of the image of Earth was described, it was interpreted as a hallucination, but later on, it was suggested that vision may indeed become sharper when leaving the atmosphere. This intense clarity my also be an important contributer to the OE (White, 2014, p. 29). This enhanced clarity might be difficult to achieve with the current resolution of VR headsets. However, the perceived clarity of Earth can be achieved through creating a contrast between the images appearing right before the view of Earth is revealed and the image of the Earth. For example, the VR journey could take the immersant through somewhat blurry undefined clouds or asteroids and then reveal a sharp and bright Earth full of vibrant details, and as such, by contrast, appearing impressively clear.

Similarly, the contrast between the Earth and the surrounding hostile space may also contribute to the perception of Earth as a beautiful and fragile living organism. Schweickart reports:
"The contrast between that bright blue and white Christmas tree ornament and the black sky, that infinite universe, really comes through"

(White, 2014, p. 36).

Through defining the contrast between the model of the Earth in VR and its surroundings we can highlight the qualities of our planet admired by astronauts during Earthgazing.

\subsubsection{Perception of Earth as a Living Organism}

Astronauts highlight how the Earth appears to be a living organism. They describe that it is always changing, you always see

"different sides of her face"

and

"different times of the day"

(White, 2014, p. 1).

We can speculate that in some way the $\mathrm{OE}$ is a form of empathy developed toward Earth as a living organism that needs care and protection from its inhabitants. Thus, it is important to put a lot of attention to the development of the Earth model in $\mathrm{VR}$, and ensure that it appears alive and dynamic. In particular, astronauts often describe the ever-changing and moving clouds and distinguishable layers of the atmosphere. Multiple layers of atmosphere and lively clouds are probably the simplest way of creating the perception of the Earth being a living organism.

\subsection{Progression of the Experience/Storyline}

\subsubsection{Earthgazing Moment}

The climax of the VR experience would be the Earthgazing moment-when the Earth is revealed and the immersant can admire its beauty. Silvia (2012) explains that a violation of expectations and surprise with an aesthetic experience leads to an increase in curiousity and positive emotion with the subject. In the case of the Earthgazing moment in space, many astronauts are not prepared for the incredible vividness and totality of the sight before them (Yaden et al., 2016). This can be attempted in a VR experience with the sudden appearance of the Earth as an incredibly detailed, three-dimensional, and visually immense object. To get the immersant ready and receptive to the introspective moment of admiring the vast beauty of the Earth, the VR experience should take them through a journey and narrative arc building up to that moment.

\subsubsection{Initial Fear}

Due to the nature of the spaceflight, the profound OE always follows the frightening experience of being aggressively rocketed into space through the burning of combustive fuel and a volatile atmosphere. As a consequence, each astronaut first has to come to terms with the possibility of death before reaching the point of relief and admiration of the beauty of the Earth.

\footnotetext{
"When a launch is successful, it is a kind of miracle and blessing that one continues to live, especially in having been transported to a new and extraordinary environment"
}

(White, 2014, p. 13) 
So in some sense the OE could be built on near-death experiences, that are also often found to be transformative (Greyson and Stevenson, 1980). Joseph Allen describes the emotional arc of the journey into space:

\begin{abstract}
"the anxious and interminable waiting, the stunning moment of ignition, the thrill of acceleration and the silent surprise of sloe-back space"
\end{abstract}

(White, 2014, p. 44).

By designing for a moment of fear and anxious anticipation in the beginning of the VR experience prior to the Earthgazing moment, we may model the emotional arc of the spaceflight journey, and help the immersant to achieve the moment of relief and peace. Since most of the potential participants of the VR experience wouldn't be familiar with an experience of being in a rocket, modeling the take-off might not be the best way of inducing a subtle amount of fear. In fact, when Gallagher et al. (2015) designed a space shuttle countdown and rocket takeoff, participants expected an experience akin to an amusement park ride, and their experiences changed to fit that expectation. A more effective method would be to incorporate into the journey an experience of a familiar event that can induce natural fear, such as a sensation of falling, or of a volatile natural phenomenon.

We want to highlight that by no means we are suggesting to design a virtual near-death experience. The design for an initial fear response should be fairly subtle, as it's important to avoid causing any traumatic virtual experiences or leading to immersants losing trust in the system, and may become disengaged to protect themselves from potential negative emotional experiences. The experience of fear should subsequently be followed by an experience of relief or resolution to ease the initial fear.

\subsubsection{Weightlessness}

Weightlessness is a significant part of astronauts' experience, that could possibly account for some part of the OE. We can't know how critical the experience of weightlessness is for the experience of $\mathrm{OE}$, as $\mathrm{OE}$ is only described in the context of a spaceflight with zero gravity. However, it is difficult to achieve on Earth without expensive equipment. Yet, the designers of a VR experience can trick the immersant to experience the sensation of floating, by intelligently creating a transition from one state in the environment to another by changing the soundscape and navigational controls. Let's take a look at how Scott Carprenter described his experiences of silence:

\begin{abstract}
"The first thing that impressed me when I got into orbit was the absolute silence. One reason for this, I suppose, was that the noisy booster had just separated and fallen away... But it was also a result, I think, of the sensation of floating"
\end{abstract}

(White, 2014, p. 19).

We can speculate that this connection between the sensation of floating and striking silence works in both directions and can be used in design of the VR experience to create experiences akin to floating.

Even though there are number of waterproof VR headsets being developed (e.g., underwater headset for virtual scuba diving
(Nagata et al., 2017) that would allow submersion in water during a virtual experience to achieve some sense of weightlessness, this is probably not a very promising direction, as it will significantly complicate the set-up of the experience and increase overall cost and complexity. Thus we propose to focus on designing for the experience of floating without submersing the immersants into water. Moreover, Gallagher et al. (2015) found in descriptions of astronauts' experiences of awe that seeing the Earth from space was more connected to the sight of the Earth, and seemingly not as much to weightlessness. Without being able to replicate a feeling of weightlessness and test its impact in VR, we are unable to empirically determine the strength of its connection to the OE. At best, we should aim to experiment with the sensation of floating felt in meditative or dream-states and assess its role as a contributor for the virtual experience of OE. Experimenting with inducing floating sensation, may allow us to investigate its importance for $\mathrm{OE}$ and guide future design.

\subsubsection{Personal Connection}

Another common theme appearing in the records of Earthgazing, is that at first, before the observer gains a sense of interconnectedness with the whole planet, they start from establishing a mental connection with something familiar, as described by Russel Schweickart:

"You finally come up across the coast of California, and you look
for those friendly things, Los Angeles and Phoenix and on across to
El Paso. And there's Houston, there's home... and you look and sure
enough there's the Astrodome-and you identify with that, it's an
attachment" (White, 2014, p. 9).

When designing a VR experience, the story line should start from establishing a familiar connection for an immersant first, before extrapolating that feeling to the full planet. This connection should not only be established with a location on the globe when Earthgazing, but even earlier, at the initial part of the experience, inviting the immersant to a virtual environment representing a familiar setting, that the immersant can easily associate with and feel at home. In our previous studies, we found that the majority of confirmed awe-inspiring moments occurred when immersants had self-relevance, such as when selecting to visit a familiar location that held personal meaning (Quesnel and Riecke, 2018). It is possible that this effect carries into the experience of the OE.

\subsubsection{Earthgazing Perspective}

Since there are multiple types of space missions, the Earthgazing could happen from three different perspectives: from inside a spaceship, from a spacewalk, and from the surface of the moon. Thus, it poses a design question for the VR experiencefrom which perspective should Earthgazing happen in VR to have the highest chances of achieving OE? The first scenario of Earthgazing from inside the spaceship has an advantage for a VR simulation, as having the cockpit in the view and serving as a foreground object would increase vection (the illusion of self-motion) (Howard and Howard, 1994). However, the reports of astronauts suggest that a spacewalk environment might be stronger in the ability to induce OE. Jack Lousma describes: 
"It's like a whole new world out there! Your perspective changes. When you're inside looking out the window, the Earth's impressive, but it's like being inside a train; you can't get your head around the flat plane of glass. But if you stand outdoors, it's like being on the front end of a locomotive as it's going down the track!"

(White, 2014, p. 40)

The third scenario of Earthgazing from the moon has been experienced only by a few astronauts, and they describe it as a different and stronger experience, as if the magnitude of the $\mathrm{OE}$ is proportional to the distances from the Earth. Michael Collins said

"There is definitely a different feeling. At 100 miles up, you are just
skimming the surface, and you don't get a feeling for the Earth as a
whole"

(White, 2014, p. 183)

Since VR allows us for more freedom in the design of the progression of the experience, we can incorporate any combination of these perspectives, possibly starting from a more familiar orbit perspective and seeing the interconnectedness of all countries, and then extrapolating the effect further while moving away from the Earth and developing a stronger awareness of how the Earth is one living organism. The opposite direction of approaching the Earth from distance can create an alternative narrative, where the immersant first will be introduced to the general idea of the fragility and unity of Earth, and then develop a more detailed and elaborated appreciation of it when Earthgazing from a greater orbital distance and noticing how a lot of the geographical locations are actually closer and more interdependent than we got used to think based on 2D political maps. The choice between these two progressions will have to be determined experimentally through user testing.

\subsubsection{Priming and Inducing the Desired State}

To implicitly guide the immersant to the desired state, we can include an altered biofeedback that would aim to guide the immersant into a calmer and more introspective state. This approach was found to be effective when participants would hear a modified sound of their footsteps, that would imply that they are heavier or lighter than they actually are, resulting in a corresponding altered perception of their body-weight and an increased motivation to exercise measured through physical properties of their walking activity (Tajadura-Jiménez et al., 2015). In a different study, an altered heart rate as biofeedback in men affected judgment of attractiveness of females in pictures (Valins, 1966). Since outer space is a very quiet environment, the only sounds heard by astronauts (other than from inside the spaceship) are the sounds produced by their own body; as such, we can include a believable soundscape that integrates an altered breathing and/or heartbeat feedback designed to calm or excite the immersant.

\subsection{Summary of Design Guidelines}

The design of the experience should focus on facilitating a journey for the immersant that gradually prepares them for the climax of the experience and assist with the accommodation and processing of it. The VR creators should think beyond the VR component of the experience and thoughtfully design the pre- and post-VR environments as an essential part of the journey. We summarize the proposed guidelines and present a possible use scenario in Figure 2, that a VR developers team could take as a starting point for designing a user journey. The designers would have to work around the technical limitations of the technology, and utilize the scientific knowledge of human perceptual and attentional processes along with artistic intuitions to "trick" immersant's perception and produce a compelling and impactful experience.

\section{EVALUATION METHODS DESIGN}

One of the challenges that arises when we strive to design a VR experience that could give immersant a glimpse of an OE, is identifying methods that will allow us to determine whether (or to what degree) the created experience was successful in evoking an experience similar to OE. In this section we will analyze the described effects of $\mathrm{OE}$ and propose a number of methods that can be used to asses these aspects. This section relies on the aspects of $\mathrm{OE}$ and spaceflight identified by Frank White and describes methods that have been used in academic research to measures the constructs related to the components of OE. In addition to OE specific methods, designers of the virtual experience should consider using VRexperience questionnaires to evaluate the general effectiveness of the experience in VR (including presence, immersion, etc.) to ensure that the designed experience is functional and compelling. Some of these questionnaires are summarized in Tcha-Tokey et al. (2016). However for this article, we will focus specifically on the methods that could be used for assessing the aspects of $\mathrm{OE}$.

Since $\mathrm{OE}$ is a very complex phenomenon, we propose to design a comprehensive system of multiple evaluation methods combining introspective, physiological, implicit attitudes and behavioral measures. Our transformative experiences framework outlines how a transformative experience such as OE can be assessed at different stages of the experience and what role VR can play in that process (Stepanova et al., 2018). Since our goal is to capture an individual's experience, introspective measures is often our best available option for assessing personal experiences. The researchers aiming to study $\mathrm{OE}$ should make use of psychometric measures, such as the awe experience scale (AWE-S) (Yaden et al., 2018), to evaluate the effectiveness of a VR experience at eliciting awe responses, which is a component of the OE. However, in order to be able to connect the individual experience of awe and the $\mathrm{OE}$ to the design of the VR experience, we need to use additional methods that can capture the progression of the individual experience through time. To achieve that, we suggest to conduct cued-recall debriefing (Bentley et al., 2005) after the VR experience with the participants, in combination with introspective open-ended interviews to look for constructs similar to the ones that astronauts describe in their interviews and the corresponding design elements of the virtual experience that might have triggered these experiences. Cued-recall debriefing 
is a situated recall method that captures on video the firstperson perspective of the participant's experience in VR, and is often successful in re-immersion that results in reporting of affective states. Phenomenological interviews complement cued-recall debriefing: while cued-recall may provide insight into the moment-to-moment thoughts and feelings during system use, interviews provide more information on the participant's history and overall experience. Below we will outline the constructs to structure the analyses of the interviews as well as non-introspective methods of assessing some of them. We have summarized the proposed relationship between experiential components and correlates, cognitive constructs and outcomes of the $\mathrm{OE}$ in the Figure 3. The specific research tools proposed in this section are summarized in Table 1 and organized based on each tool and when to implement it.

When approaching the task of measuring OE, first of all, we need to differentiate between the spaceflight experience and the OE. Even though the $\mathrm{OE}$ as a phenomenon in its current description is directly related to spaceflights (or in some cases to jet or plane flights), there is no clear understanding of what experiential aspects of a spaceflight might be related to, or necessary for the experience of OE. Thus, we will analyze these aspects separately.

\subsection{Experiential Components of a Spaceflight Experience}

Frank White identified four main aspects of the spaceflight experience that we will discuss below: changed perception of time, changed perception of space, silence, and weightlessness (White, 2014, Chapter 3).

\subsubsection{Changed Perception of Space}

There seem to be two aspects of the changed perception of space: (1) a relative perception of one's individual position in space and (2) an acquired perception of scale and position of the planet in the universe and in relation to other terrestrial bodies, as well as the distances between different locations on Earth. Earthgazing astronauts often report how they notice how different places on Earth seem to be connected and how there are

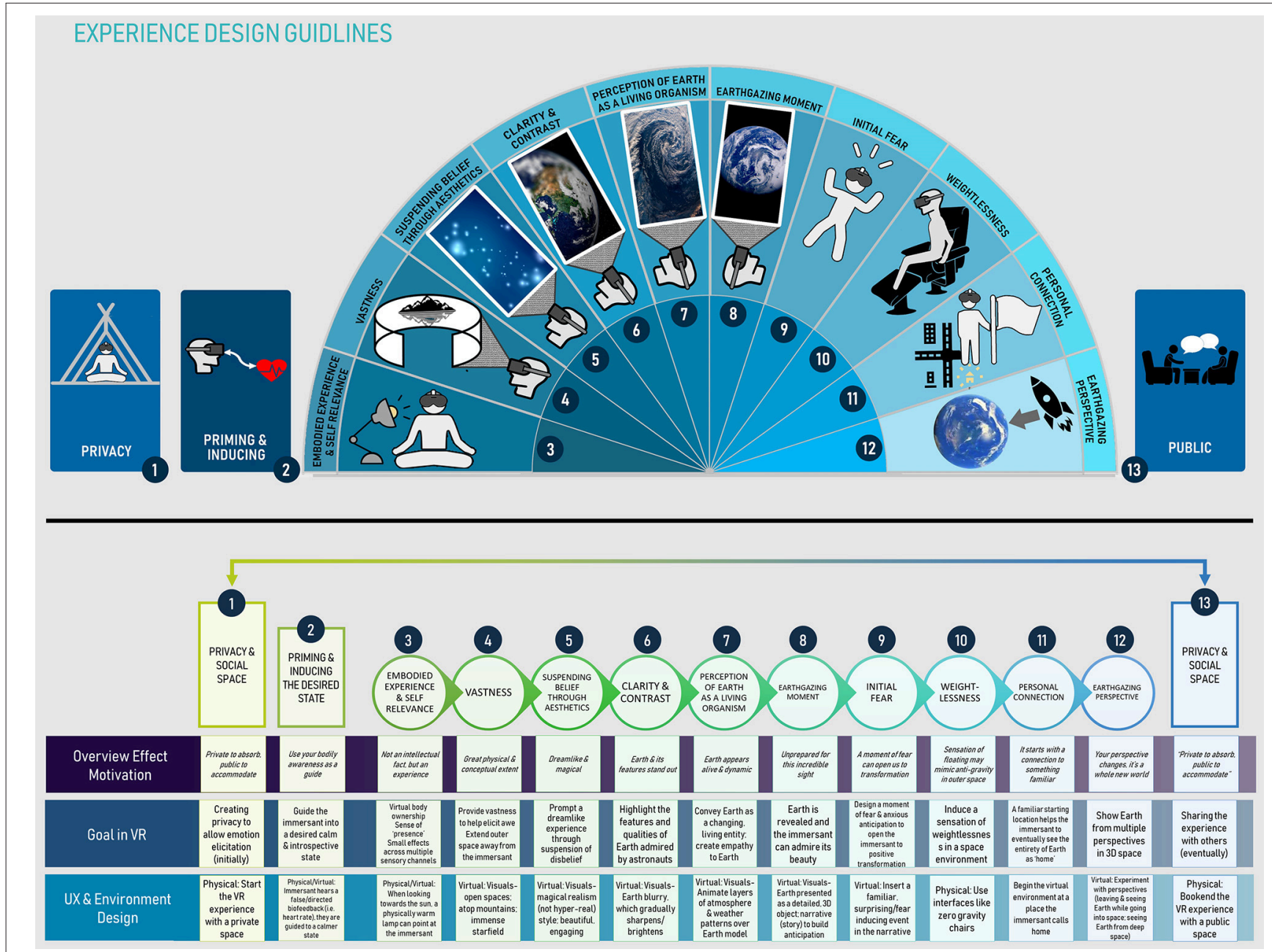

FIGURE 2 | Experience Design Guidelines summarized in a proposed use scenario. Images courtesy of NASA's public domain image library. 
no boundaries between countries; we are all neighbors. This effect can be observed in interviews, but also measured quantitatively through implicit measures. Such evaluation methods can be borrowed from studies on the effect of cognitive maps on distance estimation (where a cluttered map would result in longer distance estimation) (Thorndyke, 1981). To adapt this method for our goal in VR, we will ask participants to estimate the distances between different geographical locations, especially between and within a country, before and after the VR experience. We expect the estimation of the distances to shrink after the VR experience if the immersant experienced the OE.

John Herrington described his altered egocentric perception of direction as follows:

"I was looking at my hands as I was moving along, looking up relative to the space station, and then instantaneously, I was looking down at the space station, and I hadn't moved. My mind was suddenly telling me I was looking down rather than up"

(White, 2014, p. 20).

This disorientation can be measured through interviews and cueing the estimated orientation of the participant. It can be induced through interaction of navigation interface and body position and visuals slowly drifting off from each other, like in redirected walking (Zhang et al., 2015).

\subsubsection{Changed Perception of Time}

Most straightforwardly, time perception is measured through asking participants to report a duration of certain stimuli. Thus, in our case we are proposing to query the participant after the VR experience to estimate how long they have spent in VR. However, there will be two possible explanations for an overestimation of time: the experience was found significant or emotional (DroitVolet and Meck, 2007), or that it was uninteresting or unpleasant and time "dragged on" (Sackett et al., 2010). These will have to be disambiguated through interview data in order to be understood. Scott Carpenter stated:

"I felt a curious compression of time, as if the speed at which I traveled had some effect on the length of the moments I spent there and packed them too tightly on top of one another"

(White, 2014, p. 178).

Interestingly, the research on the phenomenology of awe suggests that as an emotion, awe often expands individual's perception of available time (Rudd et al., 2012). Rudd's et al. study implements a number of measures of perceived time availability that we can utilize to understand perception of time in VR: (1) The perceivedtime-availability index is a short Likert-scale embedded in a longer survey; (2) willingness to commit time to pro-social causes (e.g., volunteering) can be compared to willingness to commit money to the same pro-social causes (e.g., charity); (3) choosing

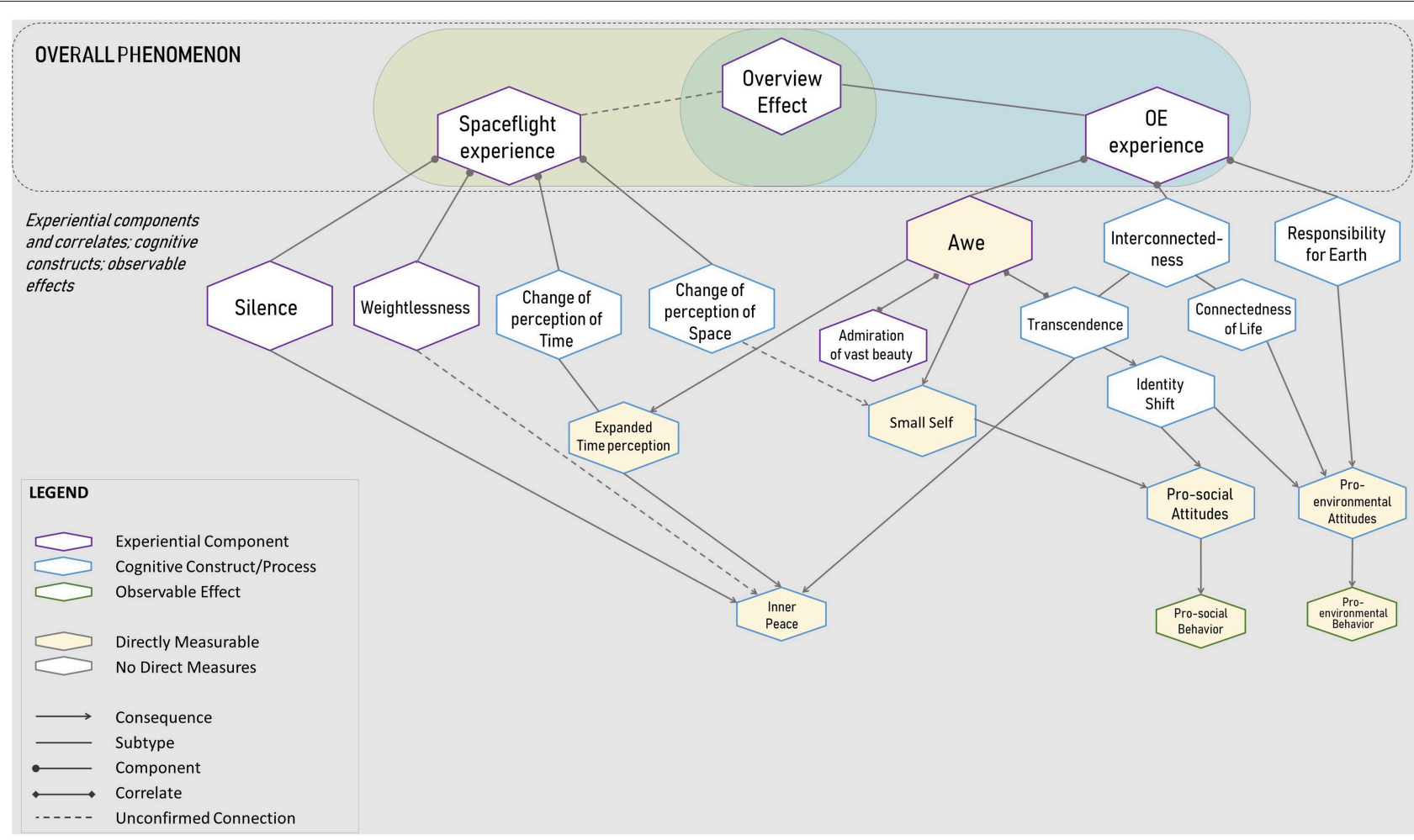

FIGURE 3 | Schematic illustration of the cognitive constructs and outcomes of the Overview Effect. The OE is traditionally described in the context of an actual spaceflight, but the experience of the OE, in principle, might be a phenomenon that could be experienced in a different context as well. Therefor some aspects of a spaceflight might be crucial for the OE experience to occur, while others might be irrelevant. 
TABLE 1 | Summary of proposed evaluation methods.

\begin{tabular}{|c|c|c|c|c|}
\hline When & Research tool & Analyses & Immediate construct & Who used the tool \\
\hline Post & Cued-Recall Debrief & Ind. position in space & Changed space perception & $\mathrm{n} / \mathrm{a}$ \\
\hline \multirow[t]{6}{*}{ Post } & Phenomenological interview & Environmental systems & Global interconnectedness & $\mathrm{n} / \mathrm{a}$ \\
\hline & & No country boarders & & $\mathrm{n} / \mathrm{a}$ \\
\hline & & Self-identifying & Shift in identity & $\mathrm{n} / \mathrm{a}$ \\
\hline & & How long was the experience? & Changed time perception & $\mathrm{n} / \mathrm{a}$ \\
\hline & & Textual analyses & Concepts similar to astronauts & Gallagher et al., 2015 \\
\hline & & Linguistic analyses "I" vs. "Us" & Identity shift & Yaden et al., 2017b \\
\hline Post & AWE-S survey & Awe Factor analyses & Awe & Yaden et al., 2018 \\
\hline Post & Inclusion of Other in Self & Self-other overlap & Connectedness with Others & Aron et al., 1992 \\
\hline \multirow[t]{2}{*}{ Prior \& post } & Geographical dist. estimation & Shrinkage of dist. est. & Space perception & Thorndyke, 1981 \\
\hline & & & Global interconnectedness & \\
\hline \multirow[t]{2}{*}{ Post } & Choose prize for a draw & Experiential vs. Material & Changed time perception/awe & Rudd et al., 2012 \\
\hline & Leave contacts for organization & Charity vs. volunteer & & \\
\hline Prior \& post & Draw yourself & Relative size & Small self & Bai et al., 2017 \\
\hline During & Wearable camera & Goose bumps & Awe & Quesnel and Riecke, 2017 \\
\hline \multirow[t]{2}{*}{ During } & Heart rate sensor & Pattern & Awe & Grewe et al., 2009 \\
\hline & & & Inner Peace & Peng et al., 2004 \\
\hline During & Skin conductance sensor & Spikes & Awe & Chirico et al., 2017 \\
\hline \multirow[t]{2}{*}{ During } & Breathing sensor/mic & Pattern & Inner Peace & Vidyarthi et al., 2012 \\
\hline & & & Awe & Shiota et al., 2011 \\
\hline Prior \& post & Observation & Pattern of movement & Inner Peace & Not found \\
\hline \multirow[t]{2}{*}{ During } & Eye- or head-tracking & attention, dwell time & Admiration of beauty & alike Massaro et al., 2012 \\
\hline & & gaze pattern & Inner Peace & Not found \\
\hline Prior \& post & IAT racial bias & Other race and self & Identity shift & Peck et al., 2013 \\
\hline Prior \& prost & IAT nature in self & Nature and self & Pro-enviromental attitudes & Schultz et al., 2004 \\
\hline \multirow[t]{2}{*}{ Post } & Offer water & Reusable vs. Disposable cup & Pro-enviomental behavior & alike Ahn et al., 2014 \\
\hline & Ask to throw out garbage & Recycling & & \\
\hline Post & "Accidentally" drop pens & $\mathrm{RT}$, and $\mathrm{N}$ of picked up pens & Pro-social behavior & Rosenberg et al., 2013 \\
\hline
\end{tabular}

between experiential goods or material goods (e.g., concert tickets over a wrist watch). In Rudd et al. (2012) the measures were all done as a set of hypothetical survey questions, but we propose to modify this method to be presented as real choices to participants through deception: for instance, participants can be informed that they could enter a draw as a reward for their participation and offered to specify a preferred prize out of available material and experiential options; or they can be offered to leave their contact details for either a volunteer organization or a charity.

\subsubsection{Silence}

The silence experienced by astronauts is hard to achieve on Earth. Earth-bound experiences that would have a similar experiential component of pure silence could be scuba diving, caving (spelunking), and possibly sensory deprivation tanks. If the design of the VR experience strives to induce the experience of silence for the immersant, they can look into the role of silence and its psychological outcomes during caving and scubadiving experiences to determine the appropriate measures for this experiential component.

\subsubsection{Weightlessness}

The phenomenology of experience of weightlessness hasn't been receiving a lot of scientific attention, due to the difficulty of achieving the experience of weightlessness on Earth. The closest studied experiences are the ones of flotation tanks. The sensory deprivation of flotation tanks submerse participants in a highly salted water, thus achieving a state close to weightlessness. A meta-analyses of 27 studies of flotation therapy supports its effectiveness for stress-management and well-being (Van Dierendonck and Te Nijenhuis, 2005). Besides most commonly reported relaxation, other effects such as altered state of consciousness, altered time-perception, and out-ofbody experiences are also reported by individuals using sensory deprivation tanks (Kjellgren et al., 2008). Since the body of research on psychological effects of weightlessness is fairly limited and its main effects intersect with other effects of OE, for the virtual OE experience we propose to add "weightlessness" as a category for analyses of the interviews of participants, but not add any separate directed measures.

\subsection{Experiential Components and Outcomes of Overview Effect}

Frank White identifies three main components of the OE:

"feeling of awe for the planet, a profound understanding of interconnectedness of all life and a renewed sense of responsibility for care of the environment"

(White, 2014, p. 2).

We discuss below how different traits of the experience could be evaluated through different methods and at various stages of processing. 


\subsubsection{Emotional Correlates}

\subsubsection{Awe}

Awe has been described as one of the key aspects of the OE. Although emotion research into awe is still in the early stages, there has been progress in determining both constructs and psychophysiological correlates to an experience of awe. Awe is a subjective experience that many individuals find difficult to put into words, which highlights its complexity. However, the body gives some clues as to when awe might occur. Among those clues is the sensation of "chills" (also seen in literature as "shivers," "frisson," "tingles"), and often their concurrence with visual piloerection, or commonly known as goose bumps ("goose flesh”) (Keltner and Haidt, 2003; Grewe et al., 2009; Benedek and Kaernbach, 2011; Nusbaum and Silvia, 2011; Stellar et al., 2017). Among the studies by Benedek and Kaernbach (2011), Quesnel and Riecke (2017), Sumpf et al. (2015), and Wassiliwizky et al. (2017), there is overall a $40 \%$ rate of goose bump elicitation in participants who watched moving/awe-inspiring videos or VR as stimuli. The consistency of this rate means goose bumps (with concurring chills or not) may be experienced by some people but not others, or that lab-induced stimuli may elicit less-intense awe experiences, theorized by Benedek and Kaernbach (2011), Silvia (2012), and Silvia et al. (2015). Other physiological measures may correlate with goose bump presence, such as heart rate variability (Grewe et al., 2009), and skin conductance (Chirico et al., 2017). The measures can be recorded along with goose bumps, and deep learning can be used to look for correlations and possible patterns of interest among multiple biosignals at once (Quesnel et al., 2018a). Additionally, observational measures of facial expression such as widen eyes and jaw drop, can be complimentary (Shiota et al., 2003), however if the experience is delivered through an HMD, access to visible facial expressions might be limited, as well as effected by the weight and fit of the headset.

Aside from psychophysiological measures, there are several studies that have analyzed awe-inspiring experiences into themes. Among these is the work of Gallagher et al. (2015), who implemented a hermeneutics exploration of syntax and language used by astronauts during the experience of awe as a part of OE. This textual analysis resulted in the creation of 34 consensus categories of awe, wonder, curiosity, and humility described in the texts by the astronauts. Such categories include: "Captured by view/drawn to phenomenon," and "Scale effects (feelings of the vastness of the universe or one's own smallness/insignificance)." In their study, the phenomenological interviews by participants who experienced a space simulation were compared to these categories and descriptions of the $\mathrm{OE}$ experience by astronauts, showing a significant overlap of the descriptions of awe. As demonstrated by Gallagher et al. (2015), the use of such categories of the OE and its features of awe and wonder are highly relevant for analyzing the immersant's experience in a VR simulated space environment.

In a recent article Yaden et al. (2018) described the development of a psychometric awe experience scale (AWE-S), that assesses six factors of an awe experience: time perception, self-loss, connectedness, vastness, physiological aspects and need for accommodation. They present a 30 item likert-scale questionnaire assessing these factors, that can be used to provide a quick quantifiable way of assessing the strength of the overall awe experience and each of the six factors following the VR experience.

Another interesting trait of awe is a "small-self" or “diminished self” (Piff et al., 2015; Bai et al., 2017)—which is associated with the trait of humility, an emotion strongly correlated to awe (Stellar et al., 2018). When experiencing awe, one's focus shifts away from themselves, toward a greater collective. The cognitive construct of "small-self" can be covertly measured through asking participants to create a visual representation of themselves in the world, specifically asking them to draw a picture of themselves in a simple environment and then the experimenter can measure the relative size one's selfrepresentation in the relation to other objects in the environment (Bai et al., 2017).

\subsubsection{Meditative state and inner peace}

Edward Gibson described his experience of Earthgazing:

\begin{abstract}
"You can see that a lot of things you worry about don't make much difference in an overall sense. The result is that you enjoy the life that is before you; you don't sweat so much about the next milestone... It allows you to have inner peace"
\end{abstract}

(White, 2014, p. 41)

This type of description of the OE suggests that the state achieved through experiencing the OE might be in effect similar to the states achieved through transcendent meditation. The inner peace in the moment can be measured through physiological correlates of meditation and relaxation, such as brainwaves (Cahn and Polich, 2013), heart rate variability, and breathing patterns (Peng et al., 2004; Cysarz and Büssing, 2005; Peressutti et al., 2010). We also propose that inner peace can be additionally measured through observations of participants' behavior before and after the experience, and coding the hectic, rushed vs. peaceful, relaxed movement patterns. However, this measure will need to be refined and validated.

\subsubsection{Attentional Measures}

VR provides the researchers with an easy access to the low resolution gaze data of the participants: even without an eyetracker, the VR headset itself provides the head movement and position data that gives an estimate of where and how the immersant is looking. Scott Carpenter talked about his experience: "I found it difficult to tear my eyes away $<\ldots>$ Everything is so new
and awe-inspiring that is difficult to concentrate for very long on
any one thing"

(White, 2014, p. 29).

By recording the head position data, we can analyze head movements and dwelling in a similar way as attention being measured with eye-trackers. If available to the researchers, then they can use HMDs with built in eye-tracking system for even more precise measure. While normally complicated to acquire in a dynamic environment, attention data comes almost "for free" with the VR technology, however the data can be challenging to interpret as there is no singular interpretation of dwell time, thus 
additional information will be required for disambiguation of the results, which can come from the interviews. The smoothness of the gaze pattern could also indicate the calmness of the state of the immersant.

\subsubsection{Interconnectedness}

The feeling of interconnectedness has two components, which can occur together or as independent experiences: the realization of the interconnectedness of life on Earth, and transcendence of one self with the universe.

\subsubsection{Interconnectedness of life}

Don Lind, as many of other astronauts, described:

\begin{abstract}
"You can't see the boundaries over which we fight wars, and in a very real way, the inhabitants of this Earth are stuck on a very beautiful, lovely little planet in an incredibly hostile space, and everybody is in the same boat"
\end{abstract}

(White, 2014, p. 43).

When seeing the Earth as a whole, astronauts come to realize how all of the living species are interconnected together. We can anticipate that this realization would lead to reduction of racial biases and acknowledging of interdependence of systems and events on our planet.

\subsubsection{Transcendence}

As in transcendent experiences, the OE leads to perceptions of one self's boundaries dissolving and instead one starts associating oneself with the whole world. As described by Russel Schweickart:

\begin{abstract}
"And that whole process of what it is you identify with begins to shift. When you go around the Earth in an hour and a half, you begin to recognize that your identity is with the whole thing, that makes a change."
\end{abstract}

(White, 2014, p. 9).

We can look for similar statements in the phenomenological interviews of participants' representing what they are identifying with and whether a shift in identity has occurred.

The feeling of connection with others is often measured through the "Inclusion of Other in Self" scale (Aron et al., 1992), that asks participants to pick between a number of venn diagrams representing the 'self'-'other' overlap. Less directly, interconnectedness can be measured through linguistic analyses of the word usage in interviews with participants, e.g., comparing the frequencies of "I" vs. "us" or "everyone" etc. (Yaden et al., 2017b). Another method that can be used for tapping into the cognitive structure is implicit attitude measures (Wittenbrink and Schwarz, 2007). This class of methods is based on the assumption that our cognitive system consists of concepts that when having stronger connections between each other will produce faster responses when triggered one after the other or together. For assessing the interconnectedness experienced as a part of the OE, we can use an implicit association test evaluating the inclusion of nature in self (Schultz et al., 2004). For instance, pre- and post-test IAT was successfully used by Peck et al. (2013) to measure the reduction of racial bias after embodying an otherrace avatar, and our pilot study of using the inclusion of nature in self IAT with an underwater VR experience (Stepanova et al.,
2017) suggested that it might be a useful measure but it is prone to noise and requires a quiet, distraction-free setting, and as such won't be good a fit for studies run outside a lab environment.

\subsubsection{Responsibility for Environment and Earth}

Many of astronauts after traveling to space return with a compulsion to take care of our planet and its inhabitants. Edgar Mitchell describes this state as:

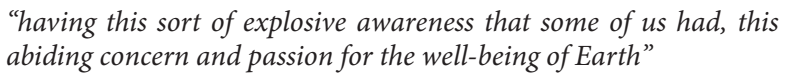

(White, 2014, p. 39)

The sense of the responsibility for the Earth can be measured through observing pro-environmental behaviors. For example, in Ahn's study of a VR experience promoting understanding of the concern of deforestation, the experimenter was "accidentally" dropping a glass of water and observing how many napkins participants will use to wipe the spilled water (Ahn et al., 2014). Similarly, we can offer the participant a glass of water and observe if they will use a reusable or disposable cup, or kindly ask them to throw out some trash on their way out and record if they went through the effort of sorting the garbage into the recycling bins. These measures will, however, be dependent on individual's beliefs of what constitutes a pro-environmental behavior.

Moreover, given the feeling of interconnectedness associated with the $\mathrm{OE}$, we would expect to observe increased prosocial behavior, that can also be assessed with observational measures. For instance, in Rosenberg's study on inducing prosocial behaviors through flying like a superman in VR, they were observing how quickly participants would reach to help the experimenter pick up the pens that he dropped, and found that both the number of pens was higher and the reaction time was slower on average in the superman condition compared to the control (Rosenberg et al., 2013).

\subsection{Considerations to Take When Applying the Measures}

\subsubsection{Individual Differences}

It is important to note that even though the OE experience seems to have common underlying traits, it is being interpreted differently by each individual (White, 2014, p. 11). For instance, Don Lind explained that religious space-travelers often tend to describe $\mathrm{OE}$ in religious terms, while people with no religious background interpreted it though different terms, often having nothing to do with spirituality (White, 2014, p. 23). Some astronauts were associating the effect of the spaceflight experience with experience of traveling to foreign countries. Joseph Allen stated

$$
\begin{aligned}
& \text { "I found that travel in space was a grand extension of the principal } \\
& \text { that taking a journey was a good thing." }
\end{aligned}
$$

(White 2014, p. 205)

Understanding whether participants have a substantial amount of traveling experience to extrapolate from will allow us to better interpret their interviews. Thus, for such a complex experience it will be especially important to collect extensive demographic data 
on the participants in order to be able to interpret their self-report data in the context of their individual background.

\subsubsection{Time Required for Accommodation of the Experience}

Not all of the astronauts report on having a profound change in their worldview, which could be because not everyone experiences the $\mathrm{OE}$, or some people choose not to discuss it, or it could take months or years to accommodate the experience, as was suggested by Charles Walker and Edgar Mitchell in their interviews with Frank White (White, 2014, p. 41). When taking measures aimed to asses a cognitive shift or behavioral change we need to be mindful that these changes require an accommodation period, which could be different for different people, and, thus, we may miss the positive effect, if we were taking the measures too soon.

\subsection{Summary of Evaluation Methods}

This section and Figure 3 illustrates how such a complex phenomenon as the $\mathrm{OE}$ requires an elaborate system of various evaluation methods assessing its immediate emotional components (e.g., admiration of the vast beauty of Earth) as well as a more long-term effects such as cognitive shifts (e.g., identity shift, expansion of time perception) and psychological (inner peace) and behavioral (pro-environmental behavior) outcomes. Only by combining multiple evaluation methods assessing different constructs and components of the $\mathrm{OE}$ we would be able to develop a comprehesive understanding of the unfolding of the phenomenon. However this conceptual framework illustrated in Figure 3 will need to be further refined and verified through additional research determining the exact relationships and interdependence of the discussed constructs. The specific methods of evaluation that we have proposed in this section and summarized in Table $\mathbf{1}$ can be substituted by alternative methods assessing the same constructs, however we insist that in order to be able to infer that the $\mathrm{OE}$ was experienced, the majority of the constructs will need to be assessed individually first and then triangulated. The Table $\mathbf{1}$ is structured around the research tools rather than the constructs in order to provide a summary of what each tool can allow to measure.

\section{EXISTING IMPLEMENTATIONS}

There were a number of attempts to elicit the $\mathrm{OE}$ using immersive technology in a research setting, as well as commercial VR games and educational experiences set in space. Commercial simulations include, but not limited to SpaceVR (Holmes, 2018), Overview (Orbital Views, 2018), Apollo 11 (Immersive VR Education Ltd., 2016), ADR1FT (505 Games, 2016), Earthlight (Opaque Space, 2017), and SpaceBuzz (SpaceBuzz Foundation, 2017). These commercial experiences are challenging to evaluate in terms of their effectiveness, as neither of the developers openly report on their methods and outcomes, thus we can only speculate about their potential based on the publicly available information, our personal experiences with the VR titles, and our discussions with some of the developers.
SpaceVR captures $360^{\circ}$ video from a camera on a low Earth orbit satellite that one can observe on a cellphone or an HMD, and was even proposed to be used in a flotation tank to support the experience with the feeling of weightlessness during the 2018 Burning Man festival (Bonasio, 2018). SpaceVR was established with a goal of bringing the $\mathrm{OE}$ to people on Earth, but we are not aware of how successful it was to this date and whether they are using any evaluation methods to assess the effect of the experience they are providing. Being a $360^{\circ}$ video, SpaceVR focuses on providing the most realistic visual perspective of an astronaut, thus it is likely successful at presenting the vastness of our planet and strives to provide high clarity images, while it lacks interactivity and narrative.

Overview provides a view of the whole galaxy striving for the accurate representation of celestial bodies and the relation between them, providing immersants with an opportunity to learn about the Earth's delicate position in the universe. It is designed to induce the change in the perception of space. This experience takes a much larger perspective than any astronaut was able to experience to this day, by providing an educational narrated experience of traveling through solar system and milky way. Even though we don't have any data on the exact effects of this experience, it was voted the best Education Experience on Steam 2018.

Apollo 11 is a VR game reconstructing the Apollo 11 lunar mission. The developers tried to provide an accurate historical replication of the event in the game environment, by reconstructing the interior of the cockpit and using NASA's actual recordings for the audio. Among the VR expereinces discussed here, this is the only one that provides an earthgazing perspective from the moon, and lets the immersants see the Earth as the "blue marble." This game presents a narrated optionally interactive story starting from a rocket launch taking the player to the moon landing. The well developed narrative starting from the initial thrill and fear of the launch seems to elicit some emotional responses in some players including awe and goosebumps based on the reviews on Steam. However, interactivity is limited to only a few instances, that were also deemed frustrating by some players, and as such the level of self-relevancy might be limited in this experience.

ADR1FT and Earthlight both are VR games providing an embodied experience of an astronaut on a space station in Earth orbit. While ADR1FT is a purely gaming experience, EarthLight is developed in collaboration with NASA to provide training opportunities for astronauts for dealing with stressful situations. Both of these experiences have higher interactivity and therefor potential for sense of self-relevance than SpaceVR and Overview, while they are less likely to provide the sense of vastness and view of the Earth as living organism, as they are task focused with a lot of attention being paid to the details of the spaceship, rather than the view of Earth. Through our own experiences with both titles, we experienced a high degree of excitement and focus on the game tasks, but neither elicited profound positive emotions similar to those within the OE. Notably, neither experience was created with a purpose of reproducing the OE, but they may inadvertently invite the $\mathrm{OE}$ experience. Anecdotally, developers of EarthLight discussed that astronauts who tried EarthLight 
mentioned that it reminded them of their actual experience in space, and they enjoyed it as a way of re-evoking their experience.

SpaceBuzz is a company in Amsterdam that aims to bring the OE experience to primary school children to educate them about science, technology and sustainability, hoping that this would contribute to forming a future generation with global consciousness. Unlike the experiences discussed above, SpaceBuzz is designed as a complex $13 \mathrm{~h}$ long experience, where the Virtual and Augmented Reality portion takes $1 \mathrm{~h}$ inside a $15 \mathrm{~m}$ long rocket and is surrounded with a $6 \mathrm{~h}$ pre-flight "astronaut training" and post-flight $6 \mathrm{~h}$ of lessons on science and technology. Thus, comparing to the experiences discussed above, SpaceBuzz is most likely to prime the participants for the experience and assist with the accommodation of it. After all, for astronauts, $\mathrm{OE}$ also spans far beyond the moment of earthgazing, so inclusion of deliberate pre- and post- experience might significantly contribute to the success of the experience. However, its success hasn't been assessed yet, as, to the best of our knowledge, the company is still in the development stage.

Besides commercial companies, the research community has also investigated the potential of VR to induce $\mathrm{OE}$ or a component of it, such as awe. Scientific publications provide more detailed information on evaluation methods of the experiences used than commercial games, however, they rarely included trailers of the experiences used, unlike the video games, thus our ability to judge which design guidelines were used might be limited.

For instance, Chirico et al. (2018) investigated how three virtual environments presenting vast stimuli, one of which was the view of Earth from space, are able to induce awe in participants. In this condition participants were able to navigate toward the Earth and watch it rotate. The results indeed show that awe-inspiring virtual environments were more likely to induce awe (measured through self-report Likert-scale questionnaire) than the control environment of a green field. Additionally, they measured the perceived vastness and need for accommodation with a Likert-scale questionnaire and found that the view of Earth was able to elicit higher sense of vastness than the control environment, but no significant differences in perceived need for accommodation was observed. This implementation presented a simple view of Earth with no storyline progression in the experience, and while participants were able to navigate through the environment, it was performed with an xBox controller and their behavior didn't have an effect on the environment, thus the sense of embodiment and self-relevance may have been limited.

Reinerman-Jones et al. (2013) created a mixed reality space capsule through which participants of their experience were passively observing an Earth moving away until turning into a blue marble and a deep space view of a path through stars. The phenomenological interviews showed more experiences of awe in the Earth condition than in deep space, and EEG recording proposed brainwave traces of the experience of awe. Their simulation replicated the narrative observed by lunar mission astronauts, but it was lacking the initial preparation and fear that are an important part of an actual experience of an astronaut. Gallagher et al. (2015) describe a number of virtual simulations of a spaceflight, all aiming to replicate the narrative of a spaceflight. Their resulting textual analyses of patricipants' interviews showed similarities to spaceflight experienced by astronauts. This indicated some effectiveness of inducing an experience similar to the OE. Both of these studies, being a scientific study of $\mathrm{OE}$, inadvertently primed their participants to have the expectation to experience a virtual spaceflight, and thus their discussion of the experience might be based on their preconceptions of what a spaceflight is supposed to be like. For instance, some of the participants in Gallagher et al. (2015) were expecting a more realistic roller-coaster like experience of spaceflight and were underwhelmed by the simulation, while others may have discussed OE in the interviews, because of their prior knowledge about the OE, rather than because of their experience in the simulation.

We have also evaluated the potential of Google Earth VR to elicit awe (Quesnel and Riecke, 2018). Google Earth provides a high resolution model of Earth, that is likely more capable of giving the sense of vastness to the immersants than the models used in the studies discussed above. It also gives immersant a choice of the location on Earth they want to go to, thus supporting the feeling of self-relevance and allowing for a personal connection to get established. We recorded self-reported measures of awe in a form of a questionnaire and an interview, as well as physiological measures in form of goose bumps. Results showed that interacting with Google Earth participants can feel awe, especially when visiting the location of their choice. As we used a commercially available product, that works much like the Google Earth one can explore on their desktop, in this study we didn't have a narrative arc, that can let participants travel through the journey that could assist with the progression of the experience and achieving desired states. It did not simulate the sense of weightlessness or use biofeedback.

In order to facilitate progression to the desired state of $\mathrm{OE}$, in our own implementation, we used an artistic approach to a VR experience inspired by the $\mathrm{OE}$, and created a physical/virtual environment called $A W E$ (Quesnel et al., 2018b) that has been demonstrated at multiple conferences and community events, as well as in a series of studies. For evaluation, we used cuedrecall, micro-phenomenological and open-ended interviews, as well as goose bumps measures, "small-self" and Implicit Association Test of implicit connection with nature. Early results are encouraging in both $A W E$ 's potential to improve well-being, and to induce a cognitive shift toward the sense of global interconnectedness. In addition to components of the $\mathrm{OE}$ experience, such as awe and realization of global interconnectedness, we also observed some instances of minor phenomenological experiences of weightlessness, which is a component of a spaceflight experience we didn't think we would be able to replicate. A detailed review of a study with $A W E$, relation of the prototype to the guidelines discussed in this paper and the comparison of the observed results to Quesnel and Riecke (2018) can be found in Stepanova et al. (in press) and forthcoming publications.

All of these implementations show indications that an experience similar to the OE may be achievable here on Earth through immersive technology. However, most of the results 
can be considered preliminary, and more research and design iteration are required in both how experiences are created, and how they are being evaluated. Simply letting immersants experience a VR environment visually representing outer space is engaging, but doesn't seem to produce a profound experience that could be identified as the OE. A more thoughtful design of the immersant's journey using prerequisites (e.g., privacy) and facilitation of transitions through the stages (e.g., from fear to awe) are necessary. At this moment, we, as a scientific community, are still far from understanding how to induce the $\mathrm{OE}$ on Earth. However, inducing some degree of its components, such as awe and interconnectedness, have indeed been demonstrated in some participants.

\section{CONCLUSION}

The OE is a fascinating, albeit extremely rare phenomenon that has been gaining more public and scientific attention in recent years. Making the OE more accessible to people can allow us to facilitate a restructuring of the value system in individuals and society. It could be an essential step in addressing major social and environmental issues that our world is facing, as well as individual psychological struggles. Even though some fundamental work has already been achieved toward generating an Earth-bound OE, we remain far from bringing an authentic, profound experience of the OE to the public. Several researchers and VR developers have been inspired to try and recreate the extraordinary OE experience in VR, yet, we are not aware of any research-based guidelines for its design being proposed and documented. Even though relevant design guidelines for the design and evaluation can be derived from research on transformative experience design (Gaggioli, 2016) or research on eliciting awe in VR (Chirico et al., 2018), specific guidelines for the design and evaluation of OE in VR have not been proposed before the current paper. This ambitious mission to comprehensively understand and create an $\mathrm{OE}$ will require an interdisciplinary team of researchers, VR developers, artists, and clinical psychologists that iteratively develop and study profound immersive experiences, and their effects on people.

In this paper, we explain what the OE is, and how it has been evaluated. With the understanding of the OE's significance in place, we then propose a series of concepts and guidelines for designing and evaluating $\mathrm{OE}$ experiences in VR to make this profound experience more accessible to researchers and the general public. As awe is a key emotional component of the $\mathrm{OE}$, some of the discussed guidelines that focus on awe and the emotional component of the experience (vastness, accomodation, privacy, etc.) can be utilized for the design of other VR experience that aim to elicit awe in general. Awe is one of the key components of the $\mathrm{OE}$ and thus can be considered a necessary, but not sufficient condition for the $\mathrm{OE}$ to manifest. Awe has been researched more than the $\mathrm{OE}$, and might be easier to measure through psychometrics (Yaden et al., 2018) and physiological measures (Quesnel and Riecke, 2018) than the other components of the $\mathrm{OE}$-interconnectedness and responsibility for Earth. Therefore, focusing on eliciting awe first would be an important first step in the iterative development of an OE experience in VR. Indeed, in testing our $A W E$ prototype we observed several instances of indication of awe experience, and much fewer of cognitive shift and interconnectedness, with no indication of increased responsibility to the environment in the participants (Stepanova et al., in press).

We invite our peers to utilize, explore, and expand on these concepts and guidelines for both the design of the $\mathrm{OE}$ experience and the proposed evaluation methods. It is important to recognize the need for these concepts and guidelines to be validated and refined through purposefully designed studies with VR experiences. We encourage the community to become engaged in a dialogue about the conceptual structure and the methods for creating emotionally profound, positive and transformative experiences like the OE on Earth, with the use of modern technology. While VR is likely the most promising tool to give more people access to the OE experience, research is needed to investigate to what extent a simulated experience might or might not be able to achieve anything as profound as the OE.

The OE is an extraordinary and complex phenomenon, but through an iterative collaboration between VR developers and researchers we might be able to recreate and understand it better, making this profound experience accessible to people around the world.

\section{AUTHOR CONTRIBUTIONS}

Authors contributed according to their competences and interests. ES and BR conceived the main idea of the article. ES performed the literature review on Overview Effect, and DQ on awe. ES wrote most of the first draft of the manuscript, and DQ added sections on aesthetics, awe and neurophenomenology. BR provided suggestions to the draft and ES and DQ together iterated on the draft to form the final manuscript. BR supervised the entire work. All authors contributed to the manuscript, read, and approved the final version.

\section{FUNDING}

Funding provided through NSERC R619563 and 31-611547, and Small Institutional SSHRC Grant R632273, Simon Fraser University (SFU), and Centre for Digital Media (CDM).

\section{ACKNOWLEDGMENTS}

We thank the members of the Overview Effect Institute for their support and informative discussions, as well as Center for Digital Media and NGX Interactive for their collaboration. We also would like to thank the editor and the reviewers for their very thoughtful and valuable feedback. 


\section{REFERENCES}

505 Games (2016). ADR1FT. Available online at: https://505games.com/games/ adr $1 \mathrm{ft}$

Ahn, S. J. G., Bailenson, J. N., and Park, D. (2014). Short-and long-term effects of embodied experiences in immersive virtual environments on environmental locus of control and behavior. Comput. Hum. Behav. 39, 235245. doi: 10.1016/j.chb.2014.07.025

Ahn, S. J. G., Bostick, J., Ogle, E., Nowak, K. L., McGillicuddy, K. T., and Bailenson, J. N. (2016). Experiencing nature: embodying animals in immersive virtual environments increases inclusion of nature in self and involvement with nature. J. Comput. Mediat. Commun. 21, 399-419. doi: 10.1111/jcc4.12173

Aron, A., Aron, E. N., and Smollan, D. (1992). Inclusion of other in the self scale and the structure of interpersonal closeness. J. Pers. Soc. Psychol. 63:596. doi: 10.1037/0022-3514.63.4.596

Bai, Y., Maruskin, L. A., Chen, S., Gordon, A. M., Stellar, J. E., McNeil, G. D., et al. (2017). Awe, the diminished self, and collective engagement: universals and cultural variations in the small self. J. Pers. Soc. Psychol. 113:185. doi: $10.1037 /$ pspa0000087

Bailey, J. O., Bailenson, J. N., and Casasanto, D. (2016). When does virtual embodiment change our minds? Presence 25, 222-233. doi: 10.1162/PRES_a_00263

Banakou, D., Hanumanthu, P. D., and Slater, M. (2016). Virtual embodiment of white people in a black virtual body leads to a sustained reduction in their implicit racial bias. Front. Hum. Neurosci. 10:601. doi: 10.3389/fnhum.2016.00601

Benedek, M., and Kaernbach, C. (2011). Physiological correlates and emotional specificity of human piloerection. Biol. Psychol. 86, 320-329. doi: 10.1016/j.biopsycho.2010.12.012

Bentley, T., Johnston, L., and von Baggo, K. (2005). "Evaluation using cuedrecall debrief to elicit information about a user's affective experiences," in Proceedings of the 17th Australia conference on Computer-Human Interaction: Citizens Online: Considerations for Today and the Future (Canberra, ACT: Computer-Human Interaction Special Interest Group (CHISIG) of Australia), 1-10.

Berkovich-Ohana, A., and Glicksohn, J. (2017). Meditation, absorption, transcendent experience, and affect: Tying it all together via the consciousness state space (css) model. Mindfulness 8, 68-77. doi: 10.1007/s12671-015-0481-9

Blumstein, D. T., and Saylan, C. (2007). The failure of environmental education (and how we can fix it). PLoS Biol. 5:e120. doi: 10.1371/journal.pbio. 0050120

Bonasio, A. (2018). Making the World a Better Place With Virtual Reality. Available online at: http://techtrends.tech/tech-trends/making-the-world-abetter-place-with-virtual-reality/ (accessed June 11, 2018).

Bonath, B., Noesselt, T., Martinez, A., Mishra, J., Schwiecker, K., Heinze, H.-J., et al. (2007). Neural basis of the ventriloquist illusion. Curr. Biol. 17, 1697-1703. doi: 10.1016/j.cub.2007.08.050

Boothby, E. J., Clark, M. S., and Bargh, J. A. (2014). Shared experiences are amplified. Psychol. Sci. 25, 2209-2216. doi: 10.1177/0956797614551162

Bourdin, P., Barberia, I., Oliva, R., and Slater, M. (2017). A virtual outof-body experience reduces fear of death. PLoS ONE 12:e0169343. doi: 10.1371/journal.pone.0169343

Brandt, T., Dichgans, J., and Koenig, E. (1973). Differential effects of central versus peripheral vision on egocentric and exocentric motion perception. Exp. Brain Res. 16, 476-491. doi: 10.1007/BF00234474

Cahn, B. R., and Polich, J. (2013). Meditation states and traits: EEG, ERP, and neuroimaging studies. Psychol Bull. 132, 180-211. doi: 10.1037/0033-2909.132.2.180

Chirico, A., Cipresso, P., Yaden, D. B., Biassoni, F., Riva, G., and Gaggioli, A. (2017). Effectiveness of immersive videos in inducing awe: an experimental study. Sci. Rep. 7:1218. doi: 10.1038/s41598-017-01242-0

Chirico, A., Ferrise, F., Cordella, L., and Gaggioli, A. (2018). Designing awe in virtual reality: an experimental study. Front. Psychol. 8:2351. doi: $10.3389 /$ fpsyg.2017.02351

Chirico, A., and Yaden, D. B. (2018). "Awe: a self-transcendent and sometimes transformative emotion," in The Function of Emotions, ed H. C. Lench (Cham: Springer), 221-233.
Chirico, A., Yaden, D. B., Riva, G., and Gaggioli, A. (2016). The potential of virtual reality for the investigation of awe. Front. Psychol. 7:1766. doi: 10.3389/fpsyg.2016.01766

Clark, B., and Graybiel, A. (1957). The break-off phenomenon: a feeling of separation from the earth experienced by pilots at high altitude. J. Aviat. Med. 28:121.

Csikszentmihalyi, M., and Csikszentmihalyi, I. S. (1992). Optimal Experience: Psychological Studies of Flow in Consciousness. Cambridge: Cambridge University Press.

Cysarz, D., and Büssing, A. (2005). Cardiorespiratory synchronization during zen meditation. Eur. J. Appl. Physiol. 95, 88-95. doi: 10.1007/s00421-005-1379-3

Davies, C., and Harrison, J. (1996). Osmose: towards broadening the aesthetics of virtual reality. ACM SIGGRAPH Comput. Graph. 30, 25-28. doi: $10.1145 / 240806.240808$

Droit-Volet, S., and Meck, W. H. (2007). How emotions colour our perception of time. Trends Cogn. Sci. 11, 504-513. doi: 10.1016/j.tics.2007.09.008

Ermi, L., and Mäyrä, F. (2005). Fundamental components of the gameplay experience: analysing immersion. Worlds In Play 37, 37-53.

Faris, W. B. (2004). Ordinary Enchantments: Magical Realism and the Remystification of Narrative. Nashville, TN: Vanderbilt University Press.

Festinger, L. (1962). A Theory of Cognitive Dissonance, vol. 2. Stanford: Stanford University Press.

Freeman, D., Reeve, S., Robinson, A., Ehlers, A., Clark, D., Spanlang, B., et al. (2017). Virtual reality in the assessment, understanding, and treatment of mental health disorders. Psychol. Med. 47, 2393-2400. doi: $10.1017 /$ S003329171700040X

Gaggioli, A. (2016). “Transformative experience design," in Human Computer Confluence. Transforming Human Experience Through Symbiotic Technologies (Warsaw), 96-121.

Gallagher, S., Janz, B., Reinerman, L., Trempler, J., and Bockelman, P. (2015). A Neurophenomenology of Awe and Wonder: Towards A Non-reductionist Cognitive Science. London: Springer.

Garan, R. (2015). The Orbital Perspective: Lessons in Seeing the Big Picture from a Journey of 71 Million Miles. Oakland, CA: Berrett-Koehler Publishers.

Gaver, W. W., Beaver, J., and Benford, S. (2003). "Ambiguity as a resource for design," in Proceedings of the SIGCHI Conference on Human Factors in Computing Systems (Ft. Lauderdale, FL: ACM), 233-240.

Gorisse, G., Christmann, O., Houzangbe, S., and Richir, S. (2019). From robot to virtual doppelganger: impact of visual fidelity of avatars controlled in third-person perspective on embodiment and behavior in immersive virtual environments. Front. Robot. AI 6:8. doi: 10.3389/frobt.2019.00008

Grewe, O., Kopiez, R., and Altenmüller, E. (2009). Chills as an indicator of individual emotional peaks. Ann. N. Y. Acad. Sci. 1169, 351-354. doi: 10.1111/j.1749-6632.2009.04783.x

Greyson, B., and Stevenson, I. (1980). The phenomenology of near-death experiences. Am. J. Psychiatry 137, 1193-1196. doi: 10.1176/ajp.137.10.1193

Hasler, B. S., Spanlang, B., and Slater, M. (2017). Virtual race transformation reverses racial in-group bias. PLOS ONE 12:e0174965. doi: 10.1371/journal.pone.0174965

Herrera, F., Bailenson, J., Weisz, E., Ogle, E., and Zaki, J. (2018). Building long-term empathy: a large-scale comparison of traditional and virtual reality perspective-taking. PLoS ONE 13:e0204494. doi: 10.1371/journal.pone.0204494

Herrera, G., Jordan, R., and Vera, L. (2006). Agency and presence: a common dependence on subjectivity? Presence 15, 539-552. doi: 10.1162/pres.15.5.539

Holmes, R. (2018). SpaceVR. Available online at: https://www.spacevr.co

Howard, I. P., and Howard, A. (1994). Vection: the contributions of absolute and relative visual motion. Perception 23, 745-751. doi: 10.1068/p230745

Ihle, E. C., Ritsher, J. B., and Kanas, N. (2006). Positive psychological outcomes of spaceflight: an empirical study. Aviat. Space Environ. Med. 77, 93-101.

Immersive VR Education Ltd. (2016). Apollo 11 VR. Available online at: https:/ immersivevreducation.com/apollo-11-vr/

Jerald, J. (2015). The VR Book: Human-Centered Design for Virtual Reality. New York, NY: Association for Computing Machinery; San Rafael, CA: Morgan \& Claypool.

Kandel, E. R. (2012). The Age of Insight: The Quest to Understand the Unconscious in Art, Mind, and Brain, from Vienna 1900 to the Present. New York, NY: Random House Incorporated. 
Keltner, D., and Haidt, J. (2003). Approaching awe, a moral, spiritual, and aesthetic emotion. Cogn. Emot. 17, 297-314. doi: 10.1080/02699930302297

Kitson, A., Schiphorst, T., and Riecke, B. E. (2018). "Are you dreaming? a phenomenological study on understanding lucid dreams as a tool for introspection in virtual reality," in Proceedings of the SIGCHI Conference on Human Factors in Computing Systems (Montréal, QC: ACM), 343:1-343:12.

Kjellgren, A., Lyden, F., and Norlander, T. (2008). Sensory isolation in flotation tanks: altered states of consciousness and effects on well-being. Qualitat. Report $13,636-656$

Klatzky, R. L., Thompson, W. B., Stefanucci, J. K., Gill, D., and McGee, D. K. (2017). The perceptual basis of vast space. Psychon. Bull. Rev. 24, 1870-1878. doi: 10.3758/s13423-017-1265-0

Kohr, R. L. (1983). Near-death experiences, altered states, and psi sensitivity. Anabiosis 3, 157-176.

Kraut, R., Patterson, M., Lundmark, V., Kiesler, S., Mukophadhyay, T., and Scherlis, W. (1998). Internet paradox: a social technology that reduces social involvement and psychological well-being? Amer. Psychol. 53:1017. doi: 10.1037/0003-066X.53.9.1017

Kross, E., Verduyn, P., Demiralp, E., Park, J., Lee, D. S., Lin, N., et al. (2013). Facebook use predicts declines in subjective well-being in young adults. PLoS ONE 8:e69841. doi: 10.1371/journal.pone.0069841

Levin, J., and Steele, L. (2005). The transcendent experience: conceptual, theoretical, and epidemiologic perspectives. Explore 1, 89-101. doi: $10.1016 /$ j.explore.2004.12.002

Lipinski, J., Spencer, J. P., and Samuelson, L. K. (2010). Biased feedback in spatial recall yields a violation of delta rule learning. Psychon. Bull. Rev. 17, 581-588. doi: 10.3758/PBR.17.4.581

Ma, K., and Hommel, B. (2015). The role of agency for perceived ownership in the virtual hand illusion. Conscious. Cogn. 36, 277-288. doi: 10.1016/j.concog.2015.07.008

Maister, L., Slater, M., Sanchez-Vives, M. V., and Tsakiris, M. (2015). Changing bodies changes minds: owning another body affects social cognition. Trends Cogn. Sci. 19, 6-12. doi: 10.1016/j.tics.2014.11.001

Markowitz, D. M., Laha, R., Perone, B. P., Pea, R. D., and Bailenson, J. N. (2018). Immersive virtual reality field trips facilitate learning about climate change. Front. Psychol. 9:2364. doi: 10.3389/fpsyg.2018.02364

Maselli, A., Kilteni, K., López-Moliner, J., and Slater, M. (2016). The sense of body ownership relaxes temporal constraints for multisensory integration. Sci. Rep. 6:30628. doi: 10.1038/srep30628

Massaro, D., Savazzi, F., Di Dio, C., Freedberg, D., Gallese, V., Gilli, G., et al. (2012). When art moves the eyes: a behavioral and eye-tracking study. PLoS ONE 7:e37285. doi: 10.1371/journal.pone.0037285

McDonald, M. G., Wearing, S., and Ponting, J. (2009). The nature of peak experience in wilderness. Hum. Psychol. 37:370. doi: $10.1080 / 08873260701828912$

McGurk, H., and MacDonald, J. (1976). Hearing lips and seeing voices. Nature 264:746. doi: $10.1038 / 264746 \mathrm{a} 0$

Morie, J. F., Luigi, D.-P., Lathan, C., Pettersen, M., and Vice, J. M. (2009). Scent delivery device and method of simulating scent in a virtual environment. US Patent 7,484,716

Morphew, M. E. (2001). Psychological and human factors in long duration spaceflight. McGill J. Med. 6, 74-80.

Nagata, K., Hatsushika, D., and Hashimoto, Y. (2017). "Virtual scuba diving system utilizing the sense of weightlessness underwater," in International Conference on Entertainment Computing (Tsukuba: Springer), 205-210.

Nezami, A. (2017). The Overview Effect and Counselling Psychology: Astronaut Experiences of Earth Gazing. PhD thesis, University of London.

Nusbaum, E. C., and Silvia, P. J. (2011). Shivers and timbres: personality and the experience of chills from music. Soc. Psychol. Pers. Sci. 2, 199-204. doi: 10.1177/1948550610386810

Opaque Space (2017). Earthlight. Available online at: https://www.earthlightvr. com/

Orbital Views (2018). Overview A Walk Through the Universe. Available online at: http://www.orbitalviews.com/overview

Peck, T. C., Seinfeld, S., Aglioti, S. M., and Slater, M. (2013). Putting yourself in the skin of a black avatar reduces implicit racial bias. Conscious. Cogn. 22, 779-787. doi: 10.1016/j.concog.2013.04.016
Peng, C.-K., Henry, I. C., Mietus, J. E., Hausdorff, J. M., Khalsa, G., Benson, H., et al. (2004). Heart rate dynamics during three forms of meditation. Int. J. Cardiol. 95, 19-27. doi: 10.1016/j.ijcard.2003.02.006

Peressutti, C., Martin-Gonzalez, J. M., Garcia-Manso, J. M., and Mesa, D. (2010). Heart rate dynamics in different levels of zen meditation. Int. J. Cardiol. 145, 142-146. doi: 10.1016/j.ijcard.2009.06.058

Piff, P. K., Dietze, P., Feinberg, M., Stancato, D. M., and Keltner, D. (2015). Awe, the small self, and prosocial behavior. J. Pers. Soc. Psychol. 108:883. doi: $10.1037 /$ pspi0000018

Pittera, D., Obrist, M., and Israr, A. (2017). "Hand-to-hand: an intermanual illusion of movement," in Proceedings of the 19th ACM International Conference on Multimodal Interaction (Glasgow, UK: ACM), 73-81.

Powell, R. B., Brownlee, M. T., Kellert, S. R., and Ham, S. H. (2012). From awe to satisfaction: immediate affective responses to the antarctic tourism experience. Polar Record 48, 145-156. doi: 10.1017/S003224741 0000720

Quesnel, D., DiPaola, S., and Riecke, B. E. (2018a). "Deep learning for classification of peak emotions within virtual reality systems," in International SERIES on Information Systems and Management in Creative eMedia (CreMedia), 6-11.

Quesnel, D., and Riecke, B. E. (2017). "Awestruck: natural interaction with virtual reality on eliciting awe," in 3D User Interfaces (3DUI), 2017 IEEE Symposium on (Los Angeles, CA: IEEE), 205-206.

Quesnel, D., and Riecke, B. E. (2018). Are you awed yet? How virtual reality gives us awe and goose bumps. Front. Psychol. 9:2158. doi: 10.3389/fpsyg.2018. 02158

Quesnel, D., Stepanova, E. R., Aguilar, I. A., Pennefather, P., and Riecke, B. E. (2018b). "Creating awe: artistic and scientific practices in research-based design for exploring a profound immersive installation," in 2018 IEEE Games, Entertainment, Media Conference (GEM) (Galway: IEEE), 1-207.

Ranasinghe, N., Jain, P., Karwita, S., Tolley, D., and Do, E. Y.-L. (2017). "Ambiotherm: enhancing sense of presence in virtual reality by simulating real-world environmental conditions," in Proceedings of the 2017 CHI Conference on Human Factors in Computing Systems (Denver, CO: ACM), 1731-1742.

Rauhoeft, G., Leyrer, M., Thompson, W. B., Stefanucci, J. K., Klatzky, R. L., and Mohler, B. J. (2015). "Evoking and assessing vastness in virtual environments," in Proceedings of the ACM SIGGRAPH Symposium on Applied Perception (Tübingen: ACM), 51-54.

Reinerman-Jones, L., Sollins, B., Janz, B., and Gallagher, S. (2013). Neurophenomenology: an integrated approach to exploring awe and wonder. South Afr. J. Philos. 32, 295-309. doi: 10.1080/02580136.2013.867397

Riecke, B. E. (2010). "Compelling self-motion through virtual environments without actual self-motion-using self-motion illusions ('vection') to improve vr user experience," in Virtual Reality, ed J.-J. Kim (London: InTech), 149-176.

Risso, P., Covarrubias Rodriguez, M., Bordegoni, M., and Gallace, A. (2018). Development and testing of a small-size olfactometer for the perception of food and beverages in humans. Front. Digit. Humanit. 5:7. doi: 10.3389/fdigh.2018.00007

Ritsher, J. B., Ihle, E. C., and Kanas, N. (2005). Positive psychological effects of space missions. Acta Astronaut. 57, 630-633. doi: 10.1016/j.actaastro.2005.03.005

Riva, G., Baños, R. M., Botella, C., Mantovani, F., and Gaggioli, A. (2016). Transforming experience: the potential of augmented reality and virtual reality for enhancing personal and clinical change. Front. Psychiatry 7:164. doi: $10.3389 /$ fpsyt.2016.00164

Rosenberg, R. S., Baughman, S. L., and Bailenson, J. N. (2013). Virtual superheroes: using superpowers in virtual reality to encourage prosocial behavior. PLOS ONE 8:e55003. doi: 10.1371/journal.pone.0055003

Rudd, M., Vohs, K. D., and Aaker, J. (2012). Awe expands people's perception of time, alters decision making, and enhances well-being. Psychol. Sci. 23, 1130-1136. doi: 10.1177/0956797612438731

Sackett, A. M., Meyvis, T., Nelson, L. D., Converse, B. A., and Sackett, A. L. (2010). You're having fun when time flies: the hedonic consequences of subjective time progression. Psychol. Sci. 21, 111-117. doi: 10.1177/0956797609 354832

Sanchez-Vives, M. V., and Slater, M. (2005). From presence to consciousness through virtual reality. Nat. Rev. Neurosci. 6:332. doi: 10.1038/nrn1651 
Schultz, P. W., Shriver, C., Tabanico, J. J., and Khazian, A. M. (2004). Implicit connections with nature. J. Environ. Psychol. 24, 31-42. doi: 10.1016/S0272-4944(03)00022-7

Serino, S., Pedroli, E., Keizer, A., Triberti, S., Dakanalis, A., Pallavicini, F., et al. (2016). Virtual reality body swapping: a tool for modifying the allocentric memory of the body. Cyberpsychol. Behav. Soc. Netw. 19, 127-133. doi: 10.1089/cyber.2015.0229

Sherman, W. R., and Craig, A. B. (2018). Understanding Virtual Reality: Interface, Application, and Design. San Francisco, CA: Morgan Kaufmann.

Shiota, M. N., Campos, B., and Keltner, D. (2003). The faces of positive emotion. Ann. N. Y. Acad. Sci. 1000, 296-299. doi: 10.1196/annals.1280.029

Shiota, M. N., Campos, B., Keltner, D., and Hertenstein, M. J. (2004). "Positive emotion and the regulation of interpersonal relationships," in The Regulation of Emotion, eds P. Philippot and R. S. Feldman (Mahwah, NJ: Erlbaum), $127-155$.

Shiota, M. N., Keltner, D., and Mossman, A. (2007). The nature of awe: elicitors, appraisals, and effects on self-concept. Cogn. Emot. 21, 944-963. doi: 10.1080/02699930600923668

Shiota, M. N., Neufeld, S. L., Yeung, W. H., Moser, S. E., and Perea, E. F. (2011). Feeling good: autonomic nervous system responding in five positive emotions. Emotion 11:1368. doi: 10.1037/a0024278

Silvia, P. J. (2012). "Human emotions and aesthetic experience," in Aesthetic Science: Connecting Minds, Brain and Experience, eds A. P. Shimamura and S. E. Palmer (Oxford: Oxford University Press), 250-275.

Silvia, P. J., Fayn, K., Nusbaum, E. C., and Beaty, R. E. (2015). Openness to experience and awe in response to nature and music: personality and profound aesthetic experiences. Psychol. Aesthet. Creat. Arts 9:376. doi: $10.1037 /$ aca0000028

Slater, M. (2009). Place illusion and plausibility can lead to realistic behaviour in immersive virtual environments. Philos. Trans. R. Soc. Lond. B Biol. Sci. 364, 3549-3557. doi: 10.1098/rstb.2009.0138

Slater, M. (2011). Transcending the self-the illusion of body ownership in immersive virtual reality and its impact on behaviour. $i$-Perception 2:754.

Sours, J. A. (1965). The break-off phenomenon: a precipitant of anxiety in jet aviators. Arch. Gen. Psychiatry 13, 447-456. doi: 10.1001/archpsyc.1965.01730050061011

SpaceBuzz Foundation (2017). SpaceBuzz. Available online at: https://www. spacebuzz.nl/

Stanney, K. M., and Hale, K. S. (2014). Handbook of Virtual Environments: Design, Implementation, and Applications. Boca Raton, FL: CRC Press.

Stellar, J. E., Gordon, A., Anderson, C. L., Piff, P. K., McNeil, G. D., and Keltner, D. (2018). Awe and humility. J. Pers. Soc. Psychol. 114:258. doi: $10.1037 /$ pspi0000109

Stellar, J. E., Gordon, A. M., Piff, P. K., Cordaro, D., Anderson, C. L., Bai, Y., et al. (2017). Self-transcendent emotions and their social functions: compassion, gratitude, and awe bind us to others through prosociality. Emot. Rev. 9, 200-207. doi: 10.1177/1754073916684557

Stepanova, E. R., Quesnel, D., Kitson, A., Prpa, M., and Riecke, B. E. (2017). "Virtual reality as a tool for inducing and understanding transformative experiences," in Psychonomics Society 58th Annual Meeting (Vancouver, BC).

Stepanova, E. R., Quesnel, D., and Riecke, B. E. (2018). "Transformative experiences become more accessible through virtual reality," in IEEE VR Workshop on Virtual and Augmented Reality for Good (VAR4GOOD) (Reutlingen: IEEE).

Stepanova, E. R., Quesnel, D., and Riecke, B. E. (in press). Understanding “AWE”: how a virtual journey can lead to increased connectedness. Front. Digit. Humanit.

Suedfeld, P., Brcic, J., Johnson, P. J., and Gushin, V. (2012). Personal growth following long-duration spaceflight. Acta Astronaut. 79, 118-123. doi: 10.1016/j.actaastro.2012.04.039

Sumpf, M., Jentschke, S., and Koelsch, S. (2015). Effects of aesthetic chills on a cardiac signature of emotionality. PLoS ONE 10:e130117. doi: 10.1371/journal.pone.0130117

Tajadura-Jiménez, A., Basia, M., Deroy, O., Fairhurst, M., Marquardt, N., and Bianchi-Berthouze, N. (2015). "As light as your footsteps: altering walking sounds to change perceived body weight, emotional state and gait," in Proceedings of the 33rd Annual ACM Conference on Human Factors in Computing Systems (Seoul: ACM), 2943-2952.
Tcha-Tokey, K., Loup-Escande, E., Christmann, O., Canac, G., Farin, F., and Richir, S. (2015). "Towards a user experience in immersive virtual environment model: a review," in Proceedings of the 27th Conference on l'Interaction HommeMachine (Toulouse: ACM), 26.

Tcha-Tokey, K., Loup-Escande, E., Christmann, O., and Richir, S. (2016). "A questionnaire to measure the user experience in immersive virtual environments," in Proceedings of the 2016 Virtual Reality International Conference (Laval: ACM), 19.

Thorndyke, P. W. (1981). Distance estimation from cognitive maps. Cogn. Psychol. 13, 526-550. doi: 10.1016/0010-0285(81)90019-0

Tsaur, S.-H., Yen, C.-H., and Hsiao, S.-L. (2013). Transcendent experience, flow and happiness for mountain climbers. Int. J. Tourism Res. 15, 360-374. doi: $10.1002 /$ jtr. 1881

Valentine, D. (2016). Atmosphere: context, detachment, and the view from above earth. Amer. Ethnol. 43, 511-524. doi: 10.1111/amet.12343

Valins, S. (1966). Cognitive effects of false heart-rate feedback. J. Pers. Soc. Psychol. 4:400. doi: 10.1037/h0023791

Van Dierendonck, D., and Te Nijenhuis, J. (2005). Flotation restricted environmental stimulation therapy (rest) as a stress-management tool: a meta-analysis. Psychol. Health 20, 405-412. doi: 10.1080/08870440412331 337093

Vidyarthi, J., Riecke, B. E., and Gromala, D. (2012). Sonic cradle: designing for an immersive experience of meditation by connecting respiration to music," in Proceedings of the Designing Interactive Systems Conference (Newcastle Upon Tyne, UK: ACM), 408-417.

Wassiliwizky, E., Jacobsen, T., Heinrich, J., Schneiderbauer, M., and Menninghaus, W. (2017). Tears falling on goosebumps: co-occurrence of emotional lacrimation and emotional piloerection indicates a psychophysiological climax in emotional arousal. Front. Psychol. 8:41. doi: 10.3389/fpsyg.2017. 00041

Welch, R. B., and Warren, D. H. (1980). Immediate perceptual response to intersensory discrepancy. Psychol. Bull. 88:638. doi: $10.1037 / 0033-2909.88 .3 .638$

White, F. (1998). The Overview Effect: Space Exploration and Human Evolution. Boston, MA: American Institute of Aeronautics and Astronautics.

White, F. (2014). The Overview Effect: Space Exploration and Human Evolution. Third Edition. Reston, VA: American Institute of Aeronautics and Astronautics.

Whiteford, H. A., Degenhardt, L., Rehm, J., Baxter, A. J., Ferrari, A. J., Erskine, H. E., et al. (2013). Global burden of disease attributable to mental and substance use disorders: findings from the global burden of disease study 2010. Lancet 382, 1575-1586. doi: 10.1016/S0140-6736(13) 61611-6

Whitmire, E., Benko, H., Holz, C., Ofek, E., and Sinclair, M. (2018). "Haptic revolver: touch, shear, texture, and shape rendering on a reconfigurable virtual reality controller," in Proceedings of the 2018 CHI Conference on Human Factors in Computing Systems (Montreal: ACM), 86.

Willemsen, P., Colton, M. B., Creem-Regehr, S. H., and Thompson, W. B. (2009). The effects of head-mounted display mechanical properties and field of view on distance judgments in virtual environments. ACM Trans. Appl. Percept. 6:8. doi: $10.1145 / 1498700.1498702$

Williams, K., and Harvey, D. (2001). Transcendent experience in forest environments. J. Environ. Psychol. 21, 249-260. doi: 10.1006/jevp. 2001.0204

Wilson, C. J., and Soranzo, A. (2015). The use of virtual reality in psychology: a case study in visual perception. Comput. Math. Methods Med. 2015:151702. doi: $10.1155 / 2015 / 151702$

Wilson, M. (2002). Six views of embodied cognition. Psychon. Bull. Rev. 9, 625-636. doi: 10.3758/BF03196322

Wittenbrink, B., and Schwarz, N. (2007). Implicit Measures of Attitudes. New York, NY: Guilford Press.

World Health Organization (2017). "Depression: let's talk" says WHO, as depression tops list of causes of ill health. (accessed: February 27, 2018).

Yaden, D. B., Haidt, J., Hood R. W. Jr., Vago, D. R., and Newberg, A. B. (2017a). The varieties of self-transcendent experience. Rev. Gen. Psychol. 21:143. doi: $10.1037 /$ gpr0000102

Yaden, D. B., Iwry, J., Slack, K. J., Eichstaedt, J. C., Zhao, Y., Vaillant, G. E., et al. (2016). The overview effect: awe and self-transcendent 
experience in space flight. Psychol. Consciousness 3:1. doi: 10.1037/cns00 00086

Yaden, D. B., Kaufman, S. B., Hyde, E., Chirico, A., Gaggioli, A., Zhang, J. W., et al. (2018). The development of the awe experience scale (AWES): a multifactorial measure for a complex emotion. J. Posit. Psychol. doi: 10.1080/17439760.2018.1484940. [Epub ahead of print].

Yaden, D. B., Le Nguyen, K. D., Kern, M. L., Wintering, N. A., Eichstaedt, J. C., Schwartz, H. A., et al. (2017b). The noetic quality: a multimethod exploratory study. Psychol. Conscious. 4:54. doi: $10.1037 / \mathrm{cns} 0000098$

Yee, N., and Bailenson, J. N. (2006). Walk a mile in digital shoes: the impact of embodied perspective-taking on the reduction of negative stereotyping in immersive virtual environments. Proc. Presence 24:26.

Yee, N., Bailenson, J. N., and Ducheneaut, N. (2009). The proteus effect: implications of transformed digital self-representation on online and offline behavior. Commun. Res. 36, 285-312. doi: 10.1177/0093650208330254
Zhang, R., Walker, J., and Kuhl, S. A. (2015). "Improving redirection with dynamic reorientations and gains," in Proceedings of the ACM SIGGRAPH Symposium on Applied Perception (ACM), 136-136.

Conflict of Interest Statement: The authors declare that the research was conducted in the absence of any commercial or financial relationships that could be construed as a potential conflict of interest.

Copyright (c) 2019 Stepanova, Quesnel and Riecke. This is an open-access article distributed under the terms of the Creative Commons Attribution License (CC BY). The use, distribution or reproduction in other forums is permitted, provided the original author(s) and the copyright owner(s) are credited and that the original publication in this journal is cited, in accordance with accepted academic practice. No use, distribution or reproduction is permitted which does not comply with these terms. 